\title{
Multifunctional graphene-based magnetic nanocarriers for combined hyperthermia and dual stimuli-responsive drug delivery
}

\author{
Raquel O. Rodrigues ${ }^{\mathrm{a}, \mathrm{b}}$, Giovanni Baldi ${ }^{\mathrm{c}}$, Saer Doumett ${ }^{\mathrm{c}}$, Lorena Garcia-Hevia ${ }^{\mathrm{d}}$, Juan Gallo ${ }^{\mathrm{d}}$,

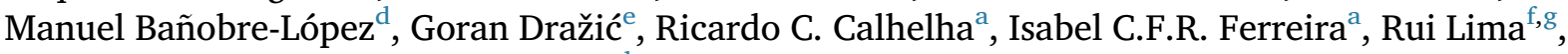 \\ Helder T. Gomes ${ }^{\mathrm{a}, *}$, Adrián M.T. Silva ${ }^{\mathrm{b}}$ \\ ${ }^{a}$ Mountain Research Centre (CIMO), ESA, Polytechnic Institute of Bragança, 5300-253 Bragança, Portugal \\ ${ }^{\mathrm{b}}$ Laboratory of Separation and Reaction Engineering - Laboratory of Catalysis and Materials (LSRE-LCM), Faculdade de Engenharia, Universidade do Porto, Rua Dr. \\ Roberto Frias, 4200-465 Porto, Portugal \\ c CERICOL, Centro Ricerche Colorobbia, Via Pietramarina 123, 50053 Sovigliana - Vinci, Firenze, Italy \\ d Advanced (magnetic) Theranostic Nanostructures Lab, Life Sciences Department, INL - International Iberian Nanotechnology Laboratory, Av. Mestre José Veiga, 4715- \\ 330 Braga, Portugal \\ e Department for Materials Chemistry, National Institute of Chemistry, Hajdrihova 19, SI-1001 Ljubljana, Slovenia \\ ${ }^{\mathrm{f}}$ MEtRICs, University of Minho, Mechanical Engineering Department, Campus de Azurém, 4800-058 Guimarães, Portugal \\ ${ }^{g}$ CEFT, Faculdade de Engenharia, Universidade do Porto, Rua Dr. Roberto Frias, 4200-465 Porto, Portugal
}

\section{A R T I C L E I N F O}

\section{Keywords:}

Graphene magnetic nanoparticles

Magnetic hyperthermia

Controlled-drug release

Cancer therapy

Doxorubicin

\begin{abstract}
A B S T R A C T
The synthesis of hydrophilic graphene-based yolk-shell magnetic nanoparticles functionalized with copolymer pluronic F-127 (GYSMNP@PF127) is herein reported to achieve an efficient multifunctional biomedical system for mild hyperthermia and stimuli-responsive drug delivery. In vitro tests revealed the extraordinary ability of GYSMNP@PF127 to act as smart stimuli-responsive multifunctional nanomedicine platform for cancer therapy, exhibiting (i) an outstanding loading capacity of $91 \%\left(\mathrm{w} / \mathrm{w}\right.$, representing $910 \mu \mathrm{g} \mathrm{mg}^{-1}$ ) of the chemotherapeutic drug doxorubicin, (ii) a high heating efficiency under an alternating (AC) magnetic field (intrinsic power loss ranging from 2.1-2.7 $\mathrm{nHm}^{2} \mathrm{~kg}^{-1}$ ), and (iii) a dual $\mathrm{pH}$ and thermal stimuli-responsive drug controlled release ( $46 \%$ at acidic tumour $\mathrm{pH}$ vs $7 \%$ at physiological $\mathrm{pH}$ ) under AC magnetic field, in just 30 min. Additionally, GYSMNP@PF127 presents optimal hydrodynamic diameter $\left(D_{H}=180 \mathrm{~nm}\right)$ with negative surface charge, high haemocompatibility for blood stream applications and tumour cellular uptake of drug nanocarriers. Due to its physicochemical, magnetic and biocompatibility properties, the developed graphene-based magnetic nanocarrier shows high promise as dual exogenous (AC field)/endogenous ( $\mathrm{pH}$ ) stimuli-responsive actuators for targeted thermo-chemotherapy, combining magnetic hyperthermia and controlled drug release triggered by the abnormal tumour environment. The presented strategy and findings can represent a new way to design and develop highly stable added-value graphene-based nanostructures for the combined treatment of cancer.
\end{abstract}

\section{Introduction}

Cancer incidence and mortality are growing worldwide at an alarming pace, emphasizing the urgent need for new strategies to combat this disease [1]. The frontiers of cancer research are currently focused on the design of multifunctional magnetic nanoparticles capable to achieve the synergistic cancer theranostics, by combining the heat effect induced by hyperthermia, the unique drug delivery properties and the improved ability of magnetic nanoparticles to accelerate the MRI relaxation process as $T_{2}$ contrast agent [2-4]. For this purpose, many magnetic nanoparticle-based drug delivery systems have been developed in the last decade [5-9]. However, the major bottleneck for their clinical theranostic achievement has been the low drug loading capacity and poor controlled-drug release of the developed magnetic nanoparticles $[9,10]$, as well as the lack of targeted drug delivery at the tumour site.

Graphene-based magnetic nanoparticles, due to their unique properties, such as high chemical and thermal stability, high charge carrier mobility and large surface area for functionalization [10,11], have the potentiality to be designed as efficient multifunctional nanocarrier systems with enhanced capability to protect the magnetic core from oxidation or dissolution in acidic environment [2,12]. Moreover, its

\footnotetext{
* Corresponding author.

E-mail address: htgomes@ipb.pt (H.T. Gomes).
} 
unique $s p^{2}$ carbon structure with $\pi-\pi$ stacking and negative surface charge, enables the adsorption of a variety of molecules, e.g. chemotherapeutic drugs, DNA and/or RNA, which can be specifically accumulated into tumours, either by active targeting or by the enhanced permeability and retention effect $[2,13]$. In addition, this non-covalent interaction mechanism allows the use of graphene-based magnetic nanoparticles as $\mathrm{pH}$ stimuli-responsive controlled drug release systems, triggered by the abnormal acidic $\mathrm{pH}$ values (around 4.5-5.5) that are found in tumour endosome/lysosome microenvironments [14]. On the other hand, the superparamagnetic core of these nanocomposites allows heat generation in the tumour under an AC magnetic field (AMF) that induces cancer cells death, by the so-called magnetic hyperthermia, and can simultaneously boost the drug release on those abnormal tissues. In fact, the combination of magnetic hyperthermia and chemotherapy has been demonstrated in clinical trials to have a synergistic effect on the cancer therapy response compared to the therapeutic effect achieved when these treatment procedures are applied alone [15]. In this regard, graphene-based magnetic nanomaterials, developed as multifunctional nanocarriers, are able to have a dramatic impact in medicine and in the treatment of cancer. However, the majority of the magnetic drug nanocarriers reported in the literature revealed a low saturation magnetization $\left(M_{s}\right)$ profile $[2,11,13,16,17]$, limiting the utility of these magnetic nanocomposites for magnetic hyperthermia. Also the possible aggregation and precipitation of graphene-based materials in the presence of electrolyte solutions, such as the body fluids [18], is an issue that needs to be addressed.

To overcome these drawbacks, a simple protocol is herein reported to synthesize a material consisting of hydrophilic graphene-based yolkshell magnetic nanoparticles (GYSMNP) functionalized with copolymer pluronic F-127 (GYSMNP@PF127). Pluronic copolymers have been investigated for the development of thermo-responsive hydrogels and drug delivery systems [19]. Particularly, pluronic F-127, with nonproprietary name poloxamer 407 , is a water-soluble and biocompatible triblock copolymer - containing hydrophilic poly(ethylene oxide) (PEO) blocks and hydrophobic poly(propylene oxide) (PPO) blocks arranged as PEO-PPO-PEO, and it is approved by the U.S. Food and Drug Administration (FDA) for use as food additive and in pharmaceutical formulations [20]. The functionalization of nanoparticles with pluronic F-127 allows the incorporation of a hydrophilic PEO corona that reduces the aggregation of nanoparticles and the adsorption of blood proteins, as well as increases the biocompatibility of the nanosystems and its colloidal stability, which prolongs blood circulation $[19,21]$. Additionally, the terminal hydroxyl functional groups allow the conjugation with selected ligands for the development of multifunctional nanosystems with high potential for active tumour targeting and therapeutic efficiency enhancement [21]. In this study, GYSMNP@ PF127 was conjugated with doxorubicin (DOX), a highly potent chemotherapeutic drug clinically used against a broad spectrum of cancers. The developed therapeutic nanosystem was thoroughly characterized and investigated as multifunctional nanocarrier to combine magnetic mild hyperthermia and stimuli-responsive drug release for thermochemotherapy.

\section{Experimental}

\subsection{Chemicals}

Ammonium hydroxide solution, $\mathrm{NH}_{4} \mathrm{OH}$ (25 wt $\%$ in $\mathrm{H}_{2} \mathrm{O}$ ), was purchased from Merck (NJ, USA). Iron (II) chloride tetrahydrate, $\mathrm{FeCl}_{2} \cdot 4 \mathrm{H}_{2} \mathrm{O}$ (99 wt\%), ethanol absolute, $\mathrm{C}_{2} \mathrm{H}_{6} \mathrm{O}$ (99.8\%), nitric acid, $\mathrm{HNO}_{3}$ (70 wt\%), copolymer pluronic F-127, $\mathrm{PEO}_{106} \mathrm{PPO}_{70} \mathrm{PEO}_{106}$ $\left(\mathrm{M}_{\mathrm{w}}=12,600\right)$, sodium chloride, $\mathrm{NaCl}(99.5 \mathrm{wt} \%)$, sodium phosphate monobasic, $\mathrm{NaH}_{2} \mathrm{PO}_{4}$ (99.0 wt\%), potassium chloride, $\mathrm{KCl}$ ( $99 \mathrm{wt} \%$ ), sodium phosphate dibasic, $\mathrm{Na}_{2} \mathrm{HPO}_{4}(99.0 \mathrm{wt} \%)$ and sodium hydroxide, $\mathrm{NaOH}$ (98 wt\%), were obtained from Sigma-Aldrich (MO, USA). Iron (III) chloride hexahydrate, $\mathrm{FeCl}_{3} \cdot 6 \mathrm{H}_{2} \mathrm{O}(97 \%)$, and formaldehyde (37 wt
\% stabilized with methanol) were supplied by Panreac (Barcelona, Spain). Resorcinol (98 wt\%) was supplied by Fisher chemicals (MA, USA). Tetraethyl orthosilicate, TEOS (98 wt\%), was obtained from Fluka (MO, USA). Doxorubicin hydrochloride, DOX (98 wt\%), was purchased from Discovery Fine Chemicals (Wimborne, UK). Physiological salt solution (PSS) with $0.9 \% \mathrm{NaCl}$ was supplied by $\mathrm{B}$. Braun Medical (Germany). Hoechst dye (BisBenzimide) and monoclonal anti- $\alpha$-tubulin antibody produced in mouse (B512) was obtained from Sigma-Aldrich (Sant Louis, MO, USA). Goat anti-Mouse IgG $(\mathrm{H}+\mathrm{L})$ Highly Cross-Adsorbed Secondary Antibody, Alexa Fluor 488 was obtained from Invitrogen (USA). The cell line HepG2 was purchased from Deutshe Sammlung von Mikroorganismen and Zellkulturen Gmbit (DSMZ). RPMI 1640 medium, hank's balanced salt solution (HBSS), fetal bovine serum (FBS), L-glutamine, trypsin-EDTA, penicillin/streptomycin solution (100 $\mathrm{U} \mathrm{mL}^{-1}$ and $100 \mathrm{mg} \mathrm{mL}^{-1}$, respectively) were purchased from Gibco Invitrogen Life Technologies (Carlsbad, CA, USA). All chemicals were used as received, without further purification. All aqueous solutions were prepared using ultrapure water $\left(18.2 \mathrm{M} \Omega \mathrm{cm}\right.$ at $25^{\circ} \mathrm{C}$ ), produced in a Milli-Q system (Millipore), or deionized water.

\subsection{Synthesis of GYSMNP}

The GYSMNP material was synthesized in two main steps: (i) synthesis of the superparamagnetic core, and (ii) formation of the graphene-based shell architecture.

In the first step, the superparamagnetic magnetite $\left(\mathrm{Fe}_{3} \mathrm{O}_{4}\right)$ core with mean diameter of $18 \mathrm{~nm}$ was synthesized through co-precipitation of $\mathrm{Fe}^{2+}$ and $\mathrm{Fe}^{3+}$ (with a molar ratio of 1:2) in a basic solution of ammonium hydroxide, at $55^{\circ} \mathrm{C}$, adapting the procedure described elsewhere [22]. Afterwards, in the second step, the graphene-based yolkshell architecture was achieved via one-pot strategy of hydrolysis and polymerisation of the precursors resorcinol, formaldehyde and TEOS, by adapting and optimizing the procedure described elsewhere [23]. In brief, an ultra-sonicated mixture of $0.25 \mathrm{~g}$ magnetite with $150 \mathrm{~mL}$ of ethanol and $50 \mathrm{~mL}$ of deionized water, was transferred into a $250 \mathrm{~mL}$ two-necked round-bottom flask. After reaching $30{ }^{\circ} \mathrm{C}, 0.10 \mathrm{~g}$ of resorcinol and $1.4 \mathrm{~mL}$ of ammonium hydroxide were added to the mixture that was magnetically stirred for $1 \mathrm{~h}$. After that, $0.15 \mathrm{~mL}$ of formaldehyde solution and $0.21 \mathrm{~mL}$ of TEOS were added dropwise and maintained under stirring at $30^{\circ} \mathrm{C}$ for $6 \mathrm{~h}$. The mixture was then heated at $80^{\circ} \mathrm{C}$ for another $8 \mathrm{~h}$ under constant stirring. The resulting magnetic product was washed by centrifugation several times with deionized water and absolute ethanol, and dried overnight at $60{ }^{\circ} \mathrm{C}$. The obtained samples were sequentially annealed under a $\mathrm{N}_{2}$ flow $\left(100 \mathrm{~cm}^{3} \mathrm{~min}^{-1}\right)$ in a tubular vertical oven at 120 and $400{ }^{\circ} \mathrm{C}$ during $60 \mathrm{~min}$ at each temperature, and then at $600{ }^{\circ} \mathrm{C}$ for $240 \mathrm{~min}$, defining a heating ramp of $2{ }^{\circ} \mathrm{C} \mathrm{min}^{-1}$. Lastly, silica (positioned between the magnetic core and the outer shell) was removed by an etching process in a strong basic solution of sodium hydroxide $\left(10 \mathrm{~mol} \mathrm{~L}^{-1} 16 \mathrm{~h}\right.$ at room temperature with stirring). The samples were washed by centrifugation several times with deionized water and absolute ethanol, and dried overnight at $60^{\circ} \mathrm{C}$, resulting in the graphene-based yolk-shell magnetic nanoparticles (GYSMNP).

\subsection{Hydrophilization of GYSMNP}

The colloidal stabilization of GYSMNP was performed by chemical functionalization of the graphene-based shell. For this purpose, an acid treatment at mild conditions was performed to incorporate carboxylic and hydroxyl groups, without compromising the magnetic core, and followed by functionalization of the copolymer pluronic F-127 (PF127) onto the surface of GYSMNP. PF127 was used as enhancer for both colloidal stabilization and biocompatibility of GYSMNP [24]. Briefly, the initial surface functionalization of GYSMNP was conducted in a $250 \mathrm{~mL}$ round-bottom flask at $65^{\circ} \mathrm{C}$ under vigorous magnetic stirring 
(C-Mag HS7, IKA). The as-synthetized GYSMNP material $\left(5 \mathrm{mg} \mathrm{mL}^{-1}\right)$ was oxidized with $\mathrm{HNO}_{3}\left(1 \mathrm{~mol} \mathrm{~L}^{-1}\right)$ during $3 \mathrm{~h}$, washed and dried overnight at $60^{\circ} \mathrm{C}$. Once the surface activated, GYSMNP $\left(2 \mathrm{mg} \mathrm{mL}^{-1}\right)$ was functionalized with PF127 (40 $\mathrm{mg} \mathrm{mL}^{-1}$ ) for $5 \mathrm{~h}$ in magnetic stirring, at room temperature. The resulting solution was washed by centrifugation $(13,000 \mathrm{rpm}, 20 \mathrm{~min})$ with deionized water to remove unbounded copolymer, and the final GYSMNP@PF127 pellet redispersed in a phosphate buffer solution or deionized water at desired concentration. The obtained hydrophilic GYSMNP@PF127 material was further used to encapsulate the chemotherapeutic drug doxorubicin (DOX).

\subsection{Characterization of GYSMNP}

The phase formation and crystallographic state of the synthesized materials were investigated in an Expert Pro Philips X-ray diffractometer. Wide angle powder X-ray diffraction (XRD) analysis was carried out using a CuKa radiation $\left(\lambda=1.54^{\circ}\right)$.

The Raman spectra of the samples were recorded at ambient temperature with a $20 \times$ objective, using a micro-Raman spectrometer apparatus (Micro-Raman DXR, Thermo scientific) with a $532 \mathrm{~nm}$ laser excitation. Curve fitting for the Raman data was carried with Origin 8.0 software using the Lorentz function.

The morphology and microstructure of the materials were evaluated using a probe $C s$ corrected High-Resolution Scanning Transmission Electron Microscope (HR-STEM), model Jeol ARM 200 CF.

The amount of carbon and magnetic core of the as-synthetized GYSMNP material was determined by thermogravimetric (TG) analysis (STA 449C Jupiter, Netzsch), heating the samples in air flow from 50 to $950{ }^{\circ} \mathrm{C}$, at $20^{\circ} \mathrm{Cmin}^{-1}$. The organic content of functionalized GYSMNP@PF127 was determined in TG analysis under $\mathrm{N}_{2}$ atmosphere by heating the samples from 50 to $550{ }^{\circ} \mathrm{C}$ at a rate of $10^{\circ} \mathrm{C} \mathrm{min}{ }^{-1}$, and comparing the results with those obtained with the as-synthetized GYSMNP, analysed under the same conditions and used as reference.

The textural properties of GYSMNP were studied using $\mathrm{N}_{2}$ adsorption-desorption isotherms obtained at $-196{ }^{\circ} \mathrm{C}$ in a Quantachrome NOVA 4200e adsorption analyser. The specific surface area $\left(S_{B E T}\right)$ was calculated by applying the Brunauer-Emmett-Teller (BET) equation [25]; the micropore volume $\left(V_{\text {micro }}\right)$ and the non-microporous surface area $\left(S_{\text {meso }}\right)$ were determined by the $t$-method using a standard isotherm [26]; and the total pore volume $\left(V_{\text {total }}\right)$ was derived from the amount of $\mathrm{N}_{2}$ adsorbed at a relative pressure close to unity $\left(P / P_{0}=0.995\right)$.

The average hydrodynamic diameter and surface charge of GYSMNP@PF127 were determined by dynamic light scattering (DLS) and zeta potential (ZP) measurements (Zetasizer Nano, Malvern Instruments) at a concentration of $0.1 \mathrm{mg} \mathrm{mL}^{-1}$ dispersed in Milli-Q water at room temperature $(n=3)$.

The $\mathrm{pH}$ at the point of zero charge $\left(\mathrm{pH}_{\mathrm{PZC}}\right)$ of the nanomaterials was determined adapting the methodology described elsewhere [27]. Briefly, solutions with varying initial $\mathrm{pH}(2-12)$ were prepared using $\mathrm{HCl}\left(1.0 \mathrm{~mol} \mathrm{~L}^{-1}\right)$ or $\mathrm{NaOH}\left(1.0 \mathrm{~mol} \mathrm{~L}^{-1}\right)$ and $20 \mathrm{~mL}$ of $\mathrm{NaCl}$ $\left(0.01 \mathrm{~mol} \mathrm{~L}^{-1}\right)$ as electrolyte. Each solution was incubated with $0.05 \mathrm{~g}$ of the material and the final $\mathrm{pH}$ was measured after $48 \mathrm{~h}$ of continuous stirring at room temperature. The $\mathrm{pH}_{\mathrm{PZC}}$ was determined by intercepting the obtained final $\mathrm{pH}$ vs. initial $\mathrm{pH}$ curve with the straight line final $\mathrm{pH}=$ initial $\mathrm{pH}$.

The Fourier transform infrared (FTIR) spectroscopy was performed with a Perkin Elmer Spectrum equipment using $\mathrm{KBr}$ pellets.

The magnetic properties of the superparamagnetic core $\left(\mathrm{Fe}_{3} \mathrm{O}_{4}\right)$ and graphene-based nanocarriers, were investigated with a superconducting quantum interference device (SQUID-VSM) magnetometer from Quantum Design. Hysteresis curves at room temperature were recorded at magnetic fields between $-20 \mathrm{kOe}$ and $20 \mathrm{kOe}$.

\subsection{Drug loading studies}

The drug loading experiments were carried out by mixing a given amount of DOX (from 50 to $500 \mu \mathrm{gL}^{-1}$ ) and a fixed amount of GYSMNP@PF127 (500 $\left.\mu \mathrm{g} \mathrm{mL} \mathrm{m}^{-1}\right)$ in a phosphate buffer solution with pH 7.4. The suspensions were kept in a shaking incubator at room temperature during $48 \mathrm{~h}$ in darkness, and the loading tests were performed in triplicate. At the end of each experiment, the GYSMNP@ PF127 material loaded with the drug (referred as GYSMNP@PF127DOX) was collected by centrifugation at $15000 \mathrm{rpm}$ for $30 \mathrm{~min}$. The supernatant (containing the free drug) was used to monitor the absorbance at $480 \mathrm{~nm}$ (characteristic of DOX), and determine the drug concentration. The drug loading efficiency and drug loading capacity were calculated using Eqs. (1) and (2), respectively.

$$
\begin{aligned}
& \text { Drug loading efficiency (\%) } \\
& =\frac{\text { Inicial concentration of drug }- \text { Drug content in the supernatant }}{\text { Inicial concentration of drug }} \times 100
\end{aligned}
$$

Drug loading capacity $\left(\mu \mathrm{g} \mathrm{mg}^{-1}\right)=\frac{\text { mass of drug loaded }}{\text { mass of GYSMNP@PF127 }}$

\section{6. $\mathrm{pH}$ and temperature-dependent drug release}

The $\mathrm{pH}$ and temperature dependent drug release of DOX loaded on GYSMNP@PF127 were evaluated in the absence of AMF (AC magnetic field). For this purpose, freeze-dried GYSMNP@PF127-DOX samples $(2.0 \mathrm{mg})$ suspended in phosphate buffer solution $(20 \mathrm{~mL})$ at physiological (pH 7.4) and acidic pH levels (pH 6.0 and 4.5), were incubated at $37^{\circ} \mathrm{C}$ (physiological body temperature) and $45^{\circ} \mathrm{C}$ (hyperthermia temperature). At selected time intervals $(0.5,1,2,3,4,6,8,24$ and $48 \mathrm{~h})$, samples were collected, centrifuged, and the supernatant used to monitor the absorbance at $480 \mathrm{~nm}$ to determine the $\mathrm{pH}$ and temperature-dependent release of DOX.

\subsection{DOX release kinetics analysis}

Drug release data were fitted to first-order (release dependent of concentration), Higuchi (release by diffusion) and Korsmeyer-Peppas ( $\log$ (cumulative drug release) vs $\log$ (time)) models in order to understand the drug release kinetics. The kinetic model that best fitted the drug release data was selected by comparing the respective regression coefficients $\left(R^{2}\right)$ of the different models. The Korsmeyer-Peppas model is used to characterize different release mechanisms from polymeric systems by using the $n$ (release exponent) value. For cylindrical shaped matrices, values of $n<0.45$ means quasi-Fickian diffusion, $n=0.45$ means Fickian diffusion, $0.45<n<0.89$ means anomalous diffusion (diffusion + erosion), $n=0.89$ means non-Fickian case II (zero order) and $n>0.89$ means non-Fickian supercase II [28].

\subsection{Validation of GYSMNP@PF127-DOX as dual pH- and AMF/ temperature-responsive drug nanocarrier}

GYSMNP@PF127 heating efficiencies were first evaluated in a hyperthermia equipment (Fives Celes, France) under an oscillating magnetic field of $H=21.0 \mathrm{kA} \mathrm{m}^{-1}$ and $340 \mathrm{kHz}$. For this purpose, $0.3 \mathrm{mg}$ of GYSMNP@PF127 was dispersed in water at a concentration of $1.5 \mathrm{mg} \mathrm{mL}^{-1}$ and placed in the mid-point of a cupper coil. Then, the temperature increase was logged as a function of time during the external AMF application using an optical fibre probe centred in the nanoparticle dispersion. The heating measurements started at stabilized room temperature and were limited to $10 \mathrm{~min}$. The specific absorption rate (SAR, W $\mathrm{g} \mathrm{Fe}^{-1}$ ) was calculated according to Eq. (3) [29]: 
$S A R=\frac{C m_{\text {water }}}{m_{\mathrm{Fe}}} \frac{\Delta T}{\Delta t}$

where $C$ is the specific heat capacity of the medium, $m_{\text {water }}$ and $m_{F e}$ are the mass of water and iron in the dispersion, respectively, and $\Delta T / \Delta t$ is the initial temperature rise rate. In addition, the intrinsic power loss (IPL, $\mathrm{nHm}^{2} \mathrm{~kg}^{-1}$ ), which is independent of the magnetic field parameters and allows direct comparison between different experiments, was calculated using Eq. (4) [30]:

$I P L=\frac{S A R}{H^{2} f}$

where $S A R$ is given by Eq. (3), $H$ is the field amplitude and $f$ the frequency used in the hyperthermia experimental setup.

On another set of experiments, the dual $\mathrm{pH}$ and AMF/temperatureresponsive drug release of GYSMNP@PF127-DOX were determined under the same AMF conditions $\left(H=21.0 \mathrm{kA} \mathrm{m}^{-1}\right.$ and $\left.f=340 \mathrm{kHz}\right)$ at a concentration of $3.0 \mathrm{mg} \mathrm{mL}^{-1}$. For this purpose, freeze-dried GYSMNP@PF127-DOX was dispersed in $0.3 \mathrm{~mL}$ of phosphate buffer at $\mathrm{pH} 7.4$ or 4.5, and maintained under AMF for 30 min. After that, the supernatant was centrifuged and used to monitor the absorbance at $480 \mathrm{~nm}$ to determine the $\mathrm{pH}$ - and $\mathrm{AMF} /$ temperature-dependent release of DOX under magnetic hyperthermia.

\subsection{In vitro cell tests}

\subsubsection{Haemocompatibility tests}

The blood-nanocarriers biocompatibility was tested by haemolysis assay according to previous reports [22,31]. Briefly, human whole blood from healthy donors was collected into $2.7 \mathrm{~mL}$ tubes (S-Monovette, Sarstedt) containing ethylenediaminetetraacetic acid (EDTA). The whole blood was diluted in a ratio 1:2 (v/v) in PSS (physiological salt solution) and centrifuged twice at $2500 \mathrm{rpm}$ for $10 \mathrm{~min}$ to isolate the red blood cells (RBCs). The isolated RBCs were diluted in $15 \mathrm{~mL}$ of PSS. $0.4 \mathrm{~mL}$ of diluted RBCs suspension was exposed to $1.6 \mathrm{~mL}$ of GYSMNP@ PF127 at different concentrations $\left(10,50,100,200,400,500 \mu \mathrm{g} \mathrm{mL}^{-1}\right)$. Positive control was obtained using the $0.4 \mathrm{~mL}$ of RBCs diluted $1.6 \mathrm{~mL}$ of PSS buffer and the negative control by adding to the diluted whole blood, deionized water in the same volume of $(1: 1, \mathrm{v} / \mathrm{v})$. Samples were incubated on an orbital shaker at $37{ }^{\circ} \mathrm{C}$ during $3 \mathrm{~h}$. The released haemoglobin was determined after centrifugation at $2500 \mathrm{rpm}$ for $10 \mathrm{~min}$, followed by photometric analysis of the supernatant at $570 \mathrm{~nm}$. The haemolysis ratio (HR) in percentage was calculated from the optical (OD) density using Eq. (5) [22], from two independent experiments in triplicates (mean \pm standard deviation).

$H R(\%)=\frac{O D_{\text {test sample }}-O D_{\text {negative control }}}{O D_{\text {positive control }}-O D_{\text {negative control }}} \times 100$

\subsubsection{Cell culture}

Two cell lines were used for the cytotoxicity assays, namely porcine liver primary cells (PLP2), established by some of the authors [32], and a human liver cancer cell line (HepG2). HepG2 was used for cellular uptake of drug nanocarriers. Prior to the in vitro cell studies, both cell lines were cultured in RPMI-1640 medium containing 10\% foetal bovine serum (FBS), $1 \%$ of glutaraldehyde, $1 \%$ of penicillin and $1 \%$ of streptomycin, under a humid atmosphere containing $5 \%$ of $\mathrm{CO}_{2}$, at $37^{\circ} \mathrm{C}$. The culture medium was replaced every two days, after the evaluation of the normal cell growth and morphology.

\subsubsection{Cell cytotoxicity assays and cellular uptake of drug nanocarriers}

The cytotoxicity of GYSMNP@PF127 and GYSMNP@PF127-DOX was assessed in PLP2 and HepG2, respectively, using the sulfurhodamine B (SRB) colorimetric assay as described elsewhere [33]. SRB assay has been widely used for drug-toxicity testing in different types of cancerous and non-cancerous cell lines [34]. Practical advances makes the SRB assay very sensitive to measure drug-induced cytotoxicity and cell proliferation even at large-scale drug-screening applications [35]. Briefly, $100 \mu \mathrm{L}$ of RPMI-1640 complete medium containing different concentrations of GYSMNP@PF127 or GYSMNP@PF127-DOX, ranging from $0.05 \mu \mathrm{g} \mathrm{mL}^{-1}$ to $50 \mu \mathrm{g} \mathrm{mL} \mathrm{m}^{-1}$, were seeded in 96-well plates. Immediately after, $100 \mu \mathrm{L}$ of RPMI-1640 complete medium containing the respective cell lines in test were added to each well, at an initial cell density of $1.0 \times 10^{4}$. In addition, control wells containing just cells with cultured medium were seeded and used as blank and control. All the assays were performed in two individual tissue-culture plates in duplicated wells $(n=4)$ and cultured in $5 \% \mathrm{CO}_{2}$, at $37^{\circ} \mathrm{C}$ for $48 \mathrm{~h}$. The percent cell viability was calculated considering the untreated cells as $100 \%$ viability. The results were used to determine the GI50, as the concentration that inhibits the growth of cells by $50 \%$.

Moreover, HepG2 cell line was incubated with $5 \mu \mathrm{g} \mathrm{m}^{-1}$ of GYSMNP@PF127-DOX during 2, 4 and 6h. Cells were fixed in 4\% paraformaldehyde. Hoechst dye was used to stain DNA. Microtubules were immunolabeled with the monoclonal anti-tubulin antibody (B512) that was recognized by a secondary goat anti-mouse immunoglobulin G (IgG) conjugated Alexa Fluor 488. Confocal microscopy images were obtained with a Carl Zeiss inverted microscope attached to the LSM 780 confocal system (software; ZEN 2010).

\section{Results and discussion}

\subsection{Synthesis and characterization of GYSMNP@PF127}

Fig. 1 illustrates the protocol of synthesis that was implemented in this study.

HR-TEM images of GYSMNP@PF127, Fig. 2(a) and (b), confirmed the formation of the yolk-shell magnetic nanostructure, namely a small cluster of magnetite cores covered by a graphene-based shell. TEM image at low magnification of the GYSMNP nanostructures is shown in Fig. S1, ESI. The average hydrodynamic dimension $\left(D_{H}\right)$ of GYSMNP@ PF127 was found to be $180 \mathrm{~nm}$ (Fig. 2(b)), with polydispersion index (PDI) of 0.14 (Table 1). Due to the enhanced permeability and retention (EPR) effect, nanoparticles with size range between 10 and $200 \mathrm{~nm}$ are ascribed to be preferentially accumulated into tumour rather than in healthy tissues [15]. Additionally, particles in the range of 100-200 nm are large enough to avoid uptake by the liver and splenic filtration [36]. Thus, the $D_{H}$ of GYSMNP@PF127 shows an optimal dimension for suitable intravenous administration and EPR effect with prolonged blood circulation.

Additionally, the zeta potential of GYSMNP, before and after functionalization with nitric acid and pluronic F-127 (PF127), was determined. A higher negative value, around - $37 \mathrm{mV}$, was determined for the functionalized samples with respect to as-synthetized GYSMNP, with zeta potential around $-17 \mathrm{mV}$ (data not shown). These results indicate the incorporation of carboxylic acid groups and negative charged PF127 on the surface of GYSMNP, with a consequent increase in the colloidal stability. Moreover, negative surface charge is ascribed to increased nanoparticle circulation by avoiding opsonisation phenomenon and their elimination from blood by macrophage cells [37].

Fig. 3 (a) shows the wide angle powder XRD patterns for both assynthesized $\mathrm{Fe}_{3} \mathrm{O}_{4}$ cores and GYSMNP. The peaks at $2 \theta$, corresponding to (111), (220), (311), (222), (400), (422), (511) and (440), are assigned to the characteristic diffraction peaks of $\mathrm{Fe}_{3} \mathrm{O}_{4}$ nanoparticles (JCPDS no. 19-629). GYSMNP showed additional peaks, namely (110) and (211), assigned to a tiny amount of secondary metal iron phase, possibly due to the reduction of magnetite during the thermal annealing procedure $\left(600{ }^{\circ} \mathrm{C}\right)$ in $\mathrm{N}_{2}$ atmosphere. A peak (002) at $24.3^{\circ}$ was also detected and assigned to the presence of the graphene-based material [38].

Results from thermogravimetric (TG) analysis under air atmosphere are shown in Fig. 3(b). The first significant weight loss below $175^{\circ} \mathrm{C}$ can be attributed to the evaporation of water molecules at the surface of the 

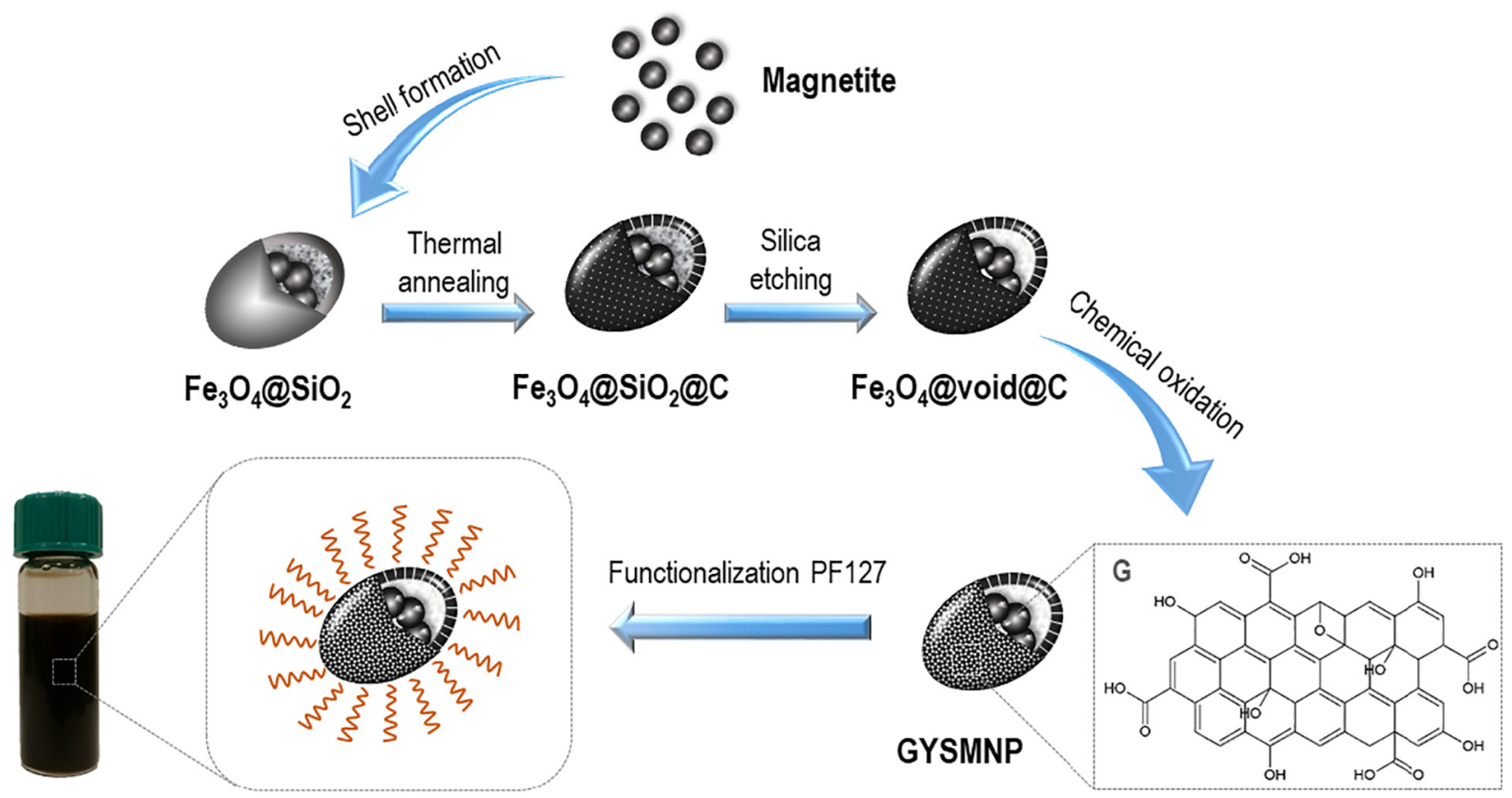

\section{Highly hydrophilic GYSMNP@PF127}

$$
\mathrm{Fe}_{3} \mathrm{O}_{4} \quad \mathrm{G} \text { Graphene-based material } \quad \mathrm{MM} \text { Copolymer pluronic F127 }
$$

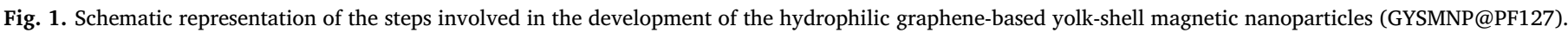

as-synthetized GYSMNP material. Above $200^{\circ} \mathrm{C}$, the weight loss can be ascribed to the desorption of oxygen functional groups in the graphenebased shells, at such temperatures typically assigned to epoxy, hydroxyl and acidic carboxylic groups [39]. The sharp mass loss observed around 400 to $600{ }^{\circ} \mathrm{C}$ corresponds to the combustion of the carbon material, suggesting a mass percentage of the graphene-based shells of $9.7 \%$. Thus, the mass percentage of magnetic core was calculated to be $88.0 \%$. Fig. 3(c) shows the Fourier transform infrared (FTIR) spectra of the samples collected at different stages of the preparation process. All samples show a FTIR spectrum with various oxygen-containing functional groups in their structure including hydroxyl, namely $\mathrm{C}-\mathrm{OH}$ $\left(3050-3800 \mathrm{~cm}^{-1}\right.$ and $\left.1070 \mathrm{~cm}^{-1}\right)$, carboxyl $(\mathrm{COOH}$, $\left.1650-1750 \mathrm{~cm}^{-1}\right)$, ketonic $\left(\mathrm{C}=\mathrm{O}, \quad 1600-1650 \mathrm{~cm}^{-1}\right.$ and $1750-1850 \mathrm{~cm}^{-1}$ ) and epoxide ( $\mathrm{C}-\mathrm{O}-\mathrm{C}, 1230-1320 \mathrm{~cm}^{-1}$ ) species, as well as $s p^{2}$-hybried $\mathrm{C}=\mathrm{C}\left(1600-1680 \mathrm{~cm}^{-1}\right)$ and alkanes $(\mathrm{C}-\mathrm{H}$, $1460 \mathrm{~cm}^{-1}$ and $1370-1385 \mathrm{~cm}^{-1}$ ), which are in accordance with previous reports for graphene oxide (GO) samples [40]. Moreover, a peak at $570 \mathrm{~cm}^{-1}$, which is the characteristic peak of the stretching vibration of $\mathrm{Fe}-\mathrm{O}$ bond from magnetite [41], was observed for all samples. Particularly, an additional peak at $1106 \mathrm{~cm}^{-1}\left(\mathrm{C}-\mathrm{O}, 1085-1300 \mathrm{~cm}^{-1}\right)$ was verified for GYSMNP@PF127 (sample (iii) in Fig. 3(c)), as a result of the incorporation of PF-127 onto its structure. The organic content of the samples was determined by TG analysis under inert atmosphere, ranging the temperature from 50 to $550^{\circ} \mathrm{C}$. Fig. 3(d) shows two sharp weight losses for GYSMNP@PF127, the first weight loss occurring between 100 and $270^{\circ} \mathrm{C}$, which can be ascribed to the decomposition of the surface oxygen groups, such as epoxy, hydroxyl and carboxylic acids [42]. The second sharp weight loss occurs between 300 and $500{ }^{\circ} \mathrm{C}$, which corresponds to the thermal decomposition of PF-127 [43], with a weight loss of $21 \%$.

Fig. 3(e) shows the Raman spectra of GYSMNP. The presence of graphene oxide is suggested by the D peak at $1350 \mathrm{~cm}^{-1}$, the conventional $\mathrm{G}$ peak at $1582 \mathrm{~cm}^{-1}$ and the 2D peak at $2816 \mathrm{~cm}^{-1}$ [44]. To better elucidate the type of graphene-based material, the three peaks
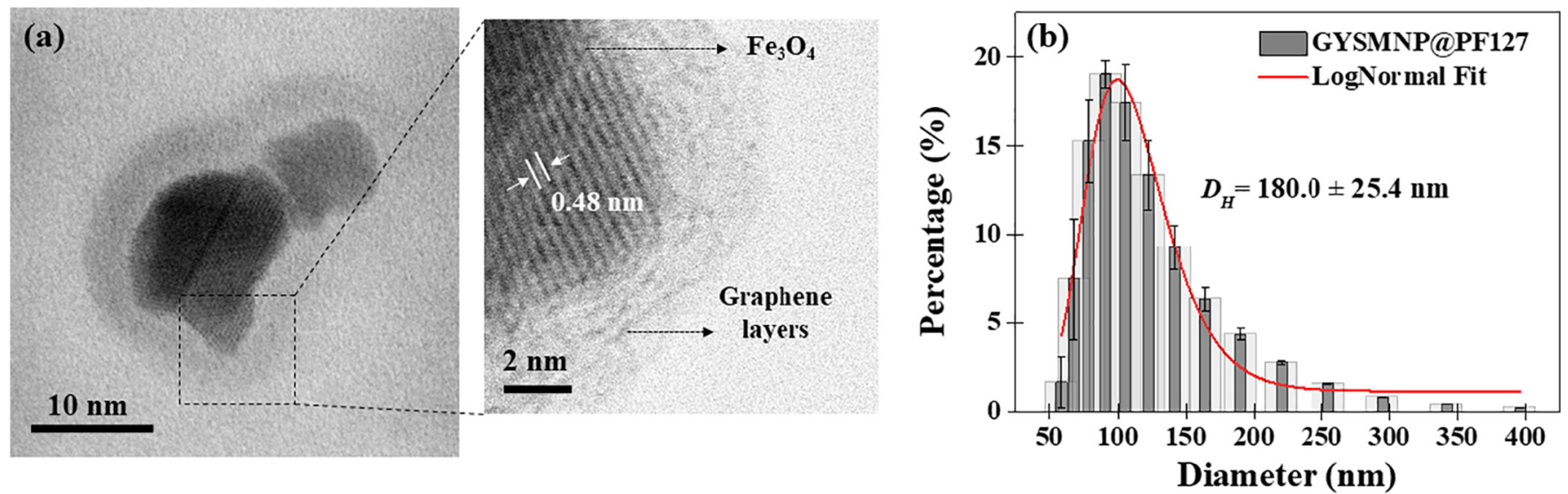

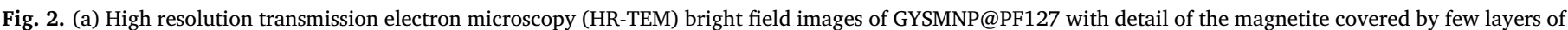
the graphene-based material; (b) DLS measurements with average hydrodynamic diameter $\left(D_{H}\right)$. 
Table 1

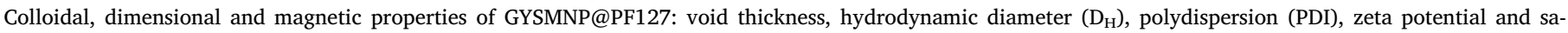
turation magnetization $\left(\mathrm{M}_{\mathrm{s}}\right)$.

\begin{tabular}{|c|c|c|c|c|c|c|}
\hline Material & Void thickness $(\mathrm{nm})^{\mathrm{a}}$ & Shell thickness $(\mathrm{nm})^{\mathrm{a}}$ & $\begin{array}{l}D_{H} \\
(\mathrm{~nm})^{\mathrm{b}}\end{array}$ & $\mathrm{PDI}^{\mathrm{b}}$ & $\begin{array}{l}\text { Zeta potential } \\
(\mathrm{mV})^{\mathrm{b}}\end{array}$ & $\begin{array}{l}\mathrm{M}_{\mathrm{s}} \\
\left(\mathrm{emug}^{-1}\right)\end{array}$ \\
\hline GYSMNP@PF127 & $0.7 \pm 0.3$ & $3.6 \pm 1.3$ & $180.0 \pm 25.4$ & $0.14 \pm 0.02$ & $-36.8 \pm 2.0$ & 69.8 \\
\hline
\end{tabular}

a Estimated by using ImageJ software from HR-STEM images as mean \pm standard deviation $(\mathrm{n}=60)$.

b Estimated by DLS and zeta potential measurements, in deionized water at $0.1 \mathrm{mg} \mathrm{mL}^{-1}$, represented as mean \pm standard deviation (n $=3$ ).

(D, G and 2D) should be analysed regarding their intensities, shapes, widths, positions and inter-correlations [45]. The G band corresponds to an $\mathrm{E}_{2 \mathrm{~g}}$ mode of hexagonal graphite and the vibration of $s p^{2}$-hybridized carbon domain, while the $\mathrm{D}$ and $2 \mathrm{D}$ peaks are assigned to structural defects $[11,13]$. The integrated peak intensity between $I_{\mathrm{D}}$ and $I_{\mathrm{G}}$ was found to be 1.61 , corresponding to a disordered graphene oxide structure $[44,46]$. Moreover, by the deconvolution of the conventional $\mathrm{G}$ band - or the apparent $\mathrm{G}$ band $\left(\mathrm{G}_{\mathrm{app}}\right)$, the actual $\mathrm{G}$ band $\left(1546 \mathrm{~cm}^{-1}\right)$ and the $\mathrm{D}^{\prime}\left(1594 \mathrm{~cm}^{-1}\right)$ can be assigned. The presence of the $\mathrm{D}^{\prime}$ band was ascribed by Kaniyoor and Ramaprabhu [47], as proof of the presence of a highly defective structure comprising few layers of wrinkled graphene-based (FlwG) structures, similar to the shell nanostructure found in the synthesized GYSMNP material (cf. Fig. 2(a)).

The magnetic hysteresis curves obtained for $\mathrm{Fe}_{3} \mathrm{O}_{4}$ and GYSMNP are shown in Fig. 3(f). GYSMNP exhibits saturation magnetization $\left(M_{s}\right)$ of 69.8 emu gmagnetite, which is close to the $M_{s}$ of the bare magnetite core, 77.7 emu gmagnetite. The $M_{s}$ for these graphene-based magnetic nanoparticles is much higher than that reported for other yolk-shell nanoparticles $[2,11,13,23]$, possibly due to the presence of superparamagnetic magnetite clusters as magnetic core. More interesting, the superparamagnetic-like behaviour of GYSMNP was accentuated, as revealed by the low-field data (inset in Fig. 3(f)), with negligible saturation remanence $\left(M_{r}\right)$ and low coercivity $\left(H_{c}\right)$, respectively 1.2 emu gmagnetite and $3.5 \mathrm{Oe}$, mainly due to lower magnetic dipolar interaction between the magnetite cores, as consequence of the graphene-based shell shielding.

Additionally, the main textural properties of the as-synthesized GYSMNP material were analysed (Table S1, ESI). The specific surface area $\left(S_{B E T}\right)$ of GYSMNP was found to be $156 \mathrm{~m}^{2} \mathrm{~g}^{-1}$. This relatively high value in comparison with uncoated magnetite, $56 \mathrm{~m}^{2} \mathrm{~g}^{-1}$ (data not shown), is ascribed to the presence of the graphene-based shell in GYSMNP. Moreover, the $V_{\text {micro }} / V_{\text {total }}$ ratio of 0.041 reveals a mesoporous structure for GYSMNP. These textural properties of GYSMNP are favourable for the encapsulation, transport and release of guest molecules, such as chemotherapeutic drugs.

\subsection{DOX loading studies}

Doxorubicin (DOX) is a cationic chemotherapeutic drug and one of the most commonly used against cancer [48]. However, it presents lethal side effects on healthy cells too [49]. Targeted drug delivery can be an effective method to overcome this issue by delivering the cargo specifically into tumours after been triggered by its abnormal acidic microenvironment. Thus, DOX was chosen to explore the drug delivery properties of GYSMNP@PF127, that shows promising potential to carry high payloads of cationic drugs due to its negative surface charge, optimal size range, large surface area, mesoporous nature and hollow cavity. The drug loading efficiency and drug loading capability were assessed by incubating DOX concentrations between 50 and $500 \mu \mathrm{g} \mathrm{mL}^{-1}$ with a fixed amount of nanoparticles $\left(500 \mu \mathrm{g} \mathrm{mL}^{-1}\right)$. The loading data are shown in Table 2.

Impressively, the drug loading capacity of GYSMNP@PF127 increases with the increase of the initial DOX concentration, reaching an outstanding $910 \mu \mathrm{g}_{\text {DOX }} \mathrm{mg}_{\text {GYSMNP@PF127 }}^{-1}$ when the initial DOX concentration is $500 \mu \mathrm{gLL}^{-1}$, which represents a $91 \%$ of drug loading efficiency $(1: 1 \mathrm{w} / \mathrm{w})$. These drug loading results show the extraordinary capability of GYSMNP@PF127 to load high contents of DOX on its high surface area. This ability can be ascribed to the $\pi-\pi$ stacking interactions between the aromatic rings of DOX and the carbonaceous structure of graphene-based nanoshells [50], as well as to some surface groups. The post-synthetic functionalization of GYSMNP allowed a high negative surface charge (zeta potential values ca. - $37 \mathrm{mV}$ (Table 1)) with $\mathrm{pH}_{\mathrm{PZC}}$ around 2 (i.e., $\mathrm{pH}$ at which the surface charge is zero), which also allows electrostatic interactions with positively charged DOX $\left(\mathrm{pK}_{\mathrm{a}}=8.3\right)$ at $\mathrm{pH} 7.4$ [51]. Thus, besides the physical bonding between DOX and the graphene-based nanoparticles, which is generally through $\pi-\pi$ stacking between the aromatic rings, the high DOX loading on GYSMNP@PF127 is also a consequence of the electrostatic interactions and the mesoporous structure of the graphene-based shell. Additionally, the mesoporous structure on GYSMNP suggests that DOX can be additionally loaded into the hollow space created by the yolk-shell architecture of these nanocarriers, increasing its loading drug capacity.

\subsection{Dual $\mathrm{pH}$ - and temperature-dependent drug release}

It is well-known that tumour microenvironment presents a weak acidic $\mathrm{pH}$ value, around $6.0-7.2$, at the tumour tissue due to the Warburg effect, which dramatically decrease to severe acidic $\mathrm{pH}$ values, around 4.5-5.5, in tumour endosome/lysosome environment [14]. The $\mathrm{pH}$ differences between the tumour microenvironment and normal tissues, with $\mathrm{pH}$ around 7.4, motivate the development of $\mathrm{pH}$-dependent/responsive nanocarriers that can be specifically designed as smart drug delivery systems triggered by acidic $\mathrm{pH}$ values. Therefore, the cumulative pH-dependent DOX release of GYSMNP@PF127-DOX was studied under different $\mathrm{pH}$ conditions (7.4, 6.0 and 4.5, corresponding to the mimicked physiological $\mathrm{pH}$, tumour microenvironment and intracellular tumour endosome/lysosome $\mathrm{pH}$ conditions, respectively) either at $37^{\circ} \mathrm{C}$ (physiological temperature) or $45^{\circ} \mathrm{C}$ (hyperthermia temperature), cf. Fig. 4.

Fig. 4 reveals that GYSMNP@PF127 has a pronounced pH- and temperature-dependent drug delivery behaviour. The drug release at these conditions takes place in two stages: (I) a rapid DOX release in the first $8 \mathrm{~h}$, followed by (II) a slower rate release till $48 \mathrm{~h}$. Analysis of stage (I) shows that just a very low amount of DOX was released at physiological pH conditions (i.e. pH 7.4), both at 37 and $45^{\circ} \mathrm{C}$. The drug release was slightly higher at $\mathrm{pH} 6.0$ than at $\mathrm{pH} 7.4$, i.e., $20 \%$ versus $12 \%$ at $37{ }^{\circ} \mathrm{C}$, and $31 \%$ versus $18 \%$ at $45^{\circ} \mathrm{C}$. But remarkably, at $\mathrm{pH} 4.5$, the drug nanocarriers show an increase of the released DOX around $47 \%$ at $37^{\circ} \mathrm{C}$, and an impressive $76 \%$ at $45^{\circ} \mathrm{C}$. For the long-period drug release, stage (II), just a maximum of $20 \%$ of DOX was released under physiological conditions. Under $\mathrm{pH} 6.0$, a maximum drug release of $25 \%$ and $36 \%$ was achieved for 37 and $45{ }^{\circ} \mathrm{C}$, respectively, whereas at $\mathrm{pH} 4.5$ a remarkable $91 \%$ of the encapsulated drug was released at $45^{\circ} \mathrm{C}$. Once again, the main reasons behind this promising $\mathrm{pH} /$ temperature-responsive drug release behaviour of the graphene-based material comes from the $\pi-\pi$ stacking between the graphene-based nanostructures and the aromatic DOX molecules, which can be easily disrupted under a mild acidic environment [13], but also due to the increased solubility of DOX caused by the protonation process [11]. In this particular example, this $\mathrm{pH}$-dependent controlled release phenomenon can be also ascribed 

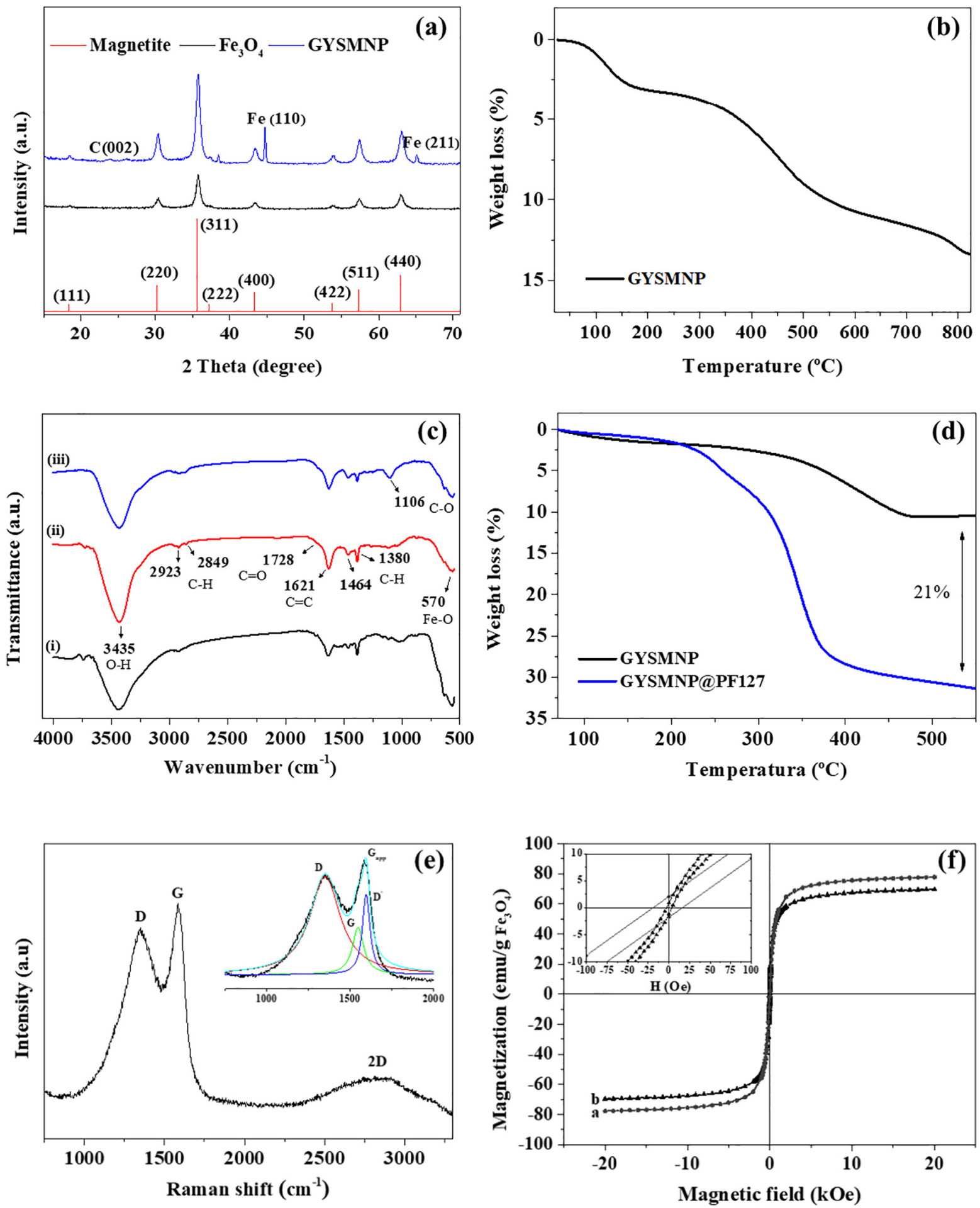

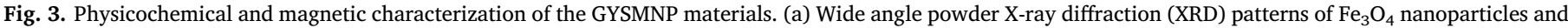

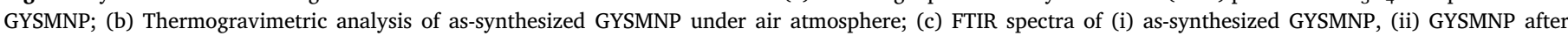

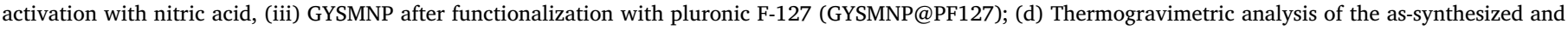

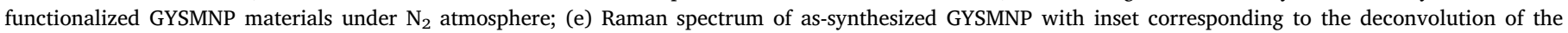

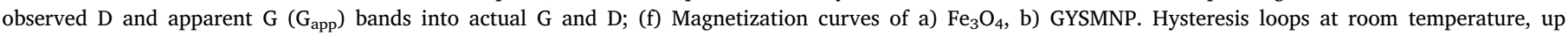
to $\pm 20 \mathrm{kOe}$; the inset is a zoom for the low field region.

to the increased protonation of the GYSMNP@PF127 nanocarrier surface as the $\mathrm{pH}$ of the aqueous solution decreases from 7.4 to 4.5 , with the associated loss of negative surface charge. This will lead to a reduction of the electrostatic attraction between GYSMNP@PF127 and DOX protonated molecules, increasing the progressive drug release.

Based on our characterizations and findings, $\mathrm{pH}$ has a much more direct effect on the release of DOX than temperature (cf. Fig. 4), since at $\mathrm{pH} 7.4$ the released DOX is almost the same at 37 or $45^{\circ} \mathrm{C}$. This difference starts to be higher with decreasing $\mathrm{pH}$ values. Thus, as $\mathrm{pH}$ becomes more acidic, the temperature seems to have a more synergetic effect. Our explanation is based on the fact that PF127 is considered a thermosensitive polymer. This is because the hydrophobicity of the PPO 
Table 2

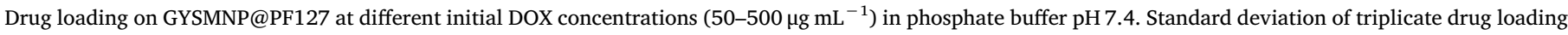
tests $(n=3)$

\begin{tabular}{|c|c|c|c|c|c|c|}
\hline & \multicolumn{6}{|c|}{ Initial DOX concentration $\left(\mu \mathrm{g} \mathrm{mL}^{-1}\right)$} \\
\hline & 50 & 100 & 200 & 300 & 400 & 500 \\
\hline Drug capacity $\left(\mu \mathrm{g} \mathrm{mg}^{-1}\right)$ & $96.0 \pm 1.0$ & $196.5 \pm 0.4$ & $394.1 \pm 1.0$ & $587.0 \pm 0.5$ & $771.2 \pm 9.0$ & $910.5 \pm 11.0$ \\
\hline Drug efficiency (\%) & $96.0 \%$ & $98.3 \%$ & $98.5 \%$ & $97.8 \%$ & $96.4 \%$ & $91.1 \%$ \\
\hline
\end{tabular}

block in Pluronic F127 changes as the temperature increases [52,53]. In our particular case, this could lead to the increase of electrostatic repulsion between PF127 and the nanosystem as the $\mathrm{pH}$ decreases, which in turn can lead to a higher release of DOX to the medium when acid $\mathrm{pH}$ and mild temperatures are combined. Overall, the $\mathrm{pH} / \mathrm{T}$-responsive drug release results obtained in this work, suggest the great ability of the designed graphene-based magnetic nanocarriers to be applied as efficient drug encapsulation and delivery systems, with an especial good $\mathrm{pH} / \mathrm{T}$ sensitivity for an intelligent and on-demand drug release on acidic tumour microenvironments.

\subsection{Drug release kinetics}

The results of the kinetic modelling, performed with the drug release data obtained for GYSMNP@PF127 (at 37 and $45^{\circ} \mathrm{C}$ and different $\mathrm{pHs}$ ), are listed in Table 3. In this study, the drug release data obtained for each $\mathrm{pH}$ and temperature tested condition were fitted to three kinetic models, namely first-order, Higuchi and Korsmeyer-Peppas. The model with the higher $R^{2}$ values (for each condition) was considered as the best model.

The first-order and Higuchi kinetic models have very low $R^{2}$ values (slightly higher for the Higuchi model). These results suggest that the drug release, under the tested conditions, is not mainly concentrationdependent or total controlled by diffusion behaviour. The kinetic model that fits better (higher $R^{2}$ ) is the Korsmeyer-Peppas model, as expected since it considers two parameters instead of one. The $n$ values calculated from the Korsmeyer-Peppas model equation were found to be lower than 0.45 , suggesting that the drug release is essentially controlled by simple quasi-Fickian diffusion mechanism.

\subsection{Validation of GYSMNP@PF127-DOX as dual $p H$ - and AMF/ temperature-responsive drug nanocarrier}

The observed $\mathrm{pH}$ - and temperature-dependence drug delivery profiles highlight the convenience of exploiting the magnetic properties of
Table 3

Drug release kinetic analysis of GYSMNP@PF127-DOX.

\begin{tabular}{|c|c|c|c|c|c|c|c|c|}
\hline \multirow[t]{2}{*}{ Temperature } & \multirow[t]{2}{*}{$\mathrm{pH}$} & \multicolumn{2}{|c|}{ First-order } & \multicolumn{2}{|c|}{ Higuchi } & \multicolumn{3}{|c|}{ Korsmeyer-Peppas } \\
\hline & & $K_{1}$ & $R^{2}$ & $H_{h}$ & $R^{2}$ & $K_{k p}$ & $n$ & $R^{2}$ \\
\hline \multirow[t]{3}{*}{$37^{\circ} \mathrm{C}$} & 7.4 & 0.001 & 0.556 & 1.456 & 0.743 & 0.009 & 0.20 & 0.932 \\
\hline & 6.0 & 0.002 & 0.655 & 2.781 & 0.816 & 0.013 & 0.23 & 0.948 \\
\hline & 4.5 & 0.005 & 0.734 & 6.074 & 0.827 & 0.033 & 0.22 & 0.962 \\
\hline \multirow[t]{3}{*}{$45^{\circ} \mathrm{C}$} & 7.4 & 0.001 & 0.575 & 1.346 & 0.758 & 0.016 & 0.13 & 0.977 \\
\hline & 6.0 & 0.002 & 0.638 & 2.608 & 0.797 & 0.027 & 0.14 & 0.980 \\
\hline & 4.5 & 0.014 & 0.849 & 6.676 & 0.818 & 0.066 & 0.14 & 0.984 \\
\hline
\end{tabular}

the magnetite cores to induce a temperature increase by external application of an AMF (AC magnetic field). Thus, in addition to an endogenous stimuli $(\mathrm{pH})$ that boosts the localized drug release on the tumour site, we can externally enhance this effect by inducing a temperature increase through magnetic hyperthermia.

The response of GYSMNP@PF127-DOX as dual pH- and temperature-sensitive drug release nanocarrier was assessed under AMF ( $f=340 \mathrm{kHz}$ and $H=21.0 \mathrm{kA} \mathrm{m}^{-1}$ ) during $30 \mathrm{~min}$. For this purpose, $3.0 \mathrm{mg} \mathrm{mL}^{-1}$ of GYSMNP@PF127-DOX, which corresponds to $1.6 \mathrm{mg} \mathrm{mL}^{-1}$ of unloaded-DOX GYSMNP@PF127, was dispersed in phosphate buffer at $\mathrm{pH} 7.4$ and 4.5. Mild hyperthermia temperature $\left(40-43^{\circ} \mathrm{C}\right.$ ) was reached between 10 and $13 \mathrm{~min}$ and maintained till the end of the hyperthermia experiment ( $30 \mathrm{~min}$ ) (Fig. 5). From the initial slope of the heating curve, SAR (specific absorption rate) and IPL (intrinsic power loss) values were estimated to be 334 and $402 \mathrm{Wg} \mathrm{Fe}^{-1}$, which correspond to 2.2 and $2.7 \mathrm{nHm}^{2} \mathrm{~kg}^{-1}$, from samples dispersed in phosphate buffer 7.4 and 4.5 , respectively. These results represent a much better heating efficiency than other magnetic nanomaterials synthesized for hyperthermia application [12,15,54], and are in agreement with IPL values $\left(0.15-3.1 \mathrm{nHm}^{2} \mathrm{~kg}^{-1}\right)$ of commercial ferrofluids $[15,55]$. Moreover, these SAR and IPL values are similar to those obtained for the unloaded-DOX GYSMNP@PF127 (Fig. S2, ESI), showing that the loading of the drug does not significantly change the

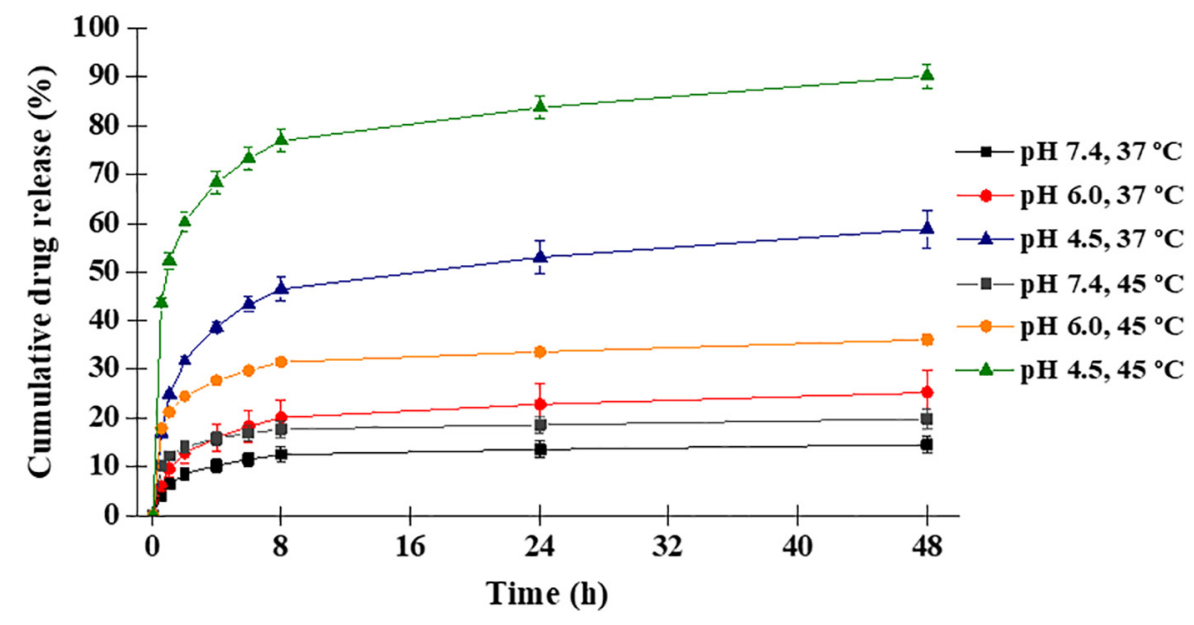

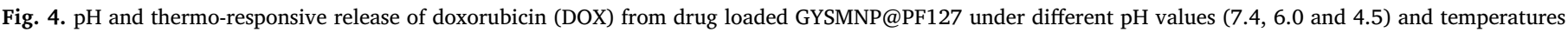
$\left(37\right.$ and $\left.45^{\circ} \mathrm{C}\right)$. Standard deviation of triplicate drug release tests $(n=3)$. 

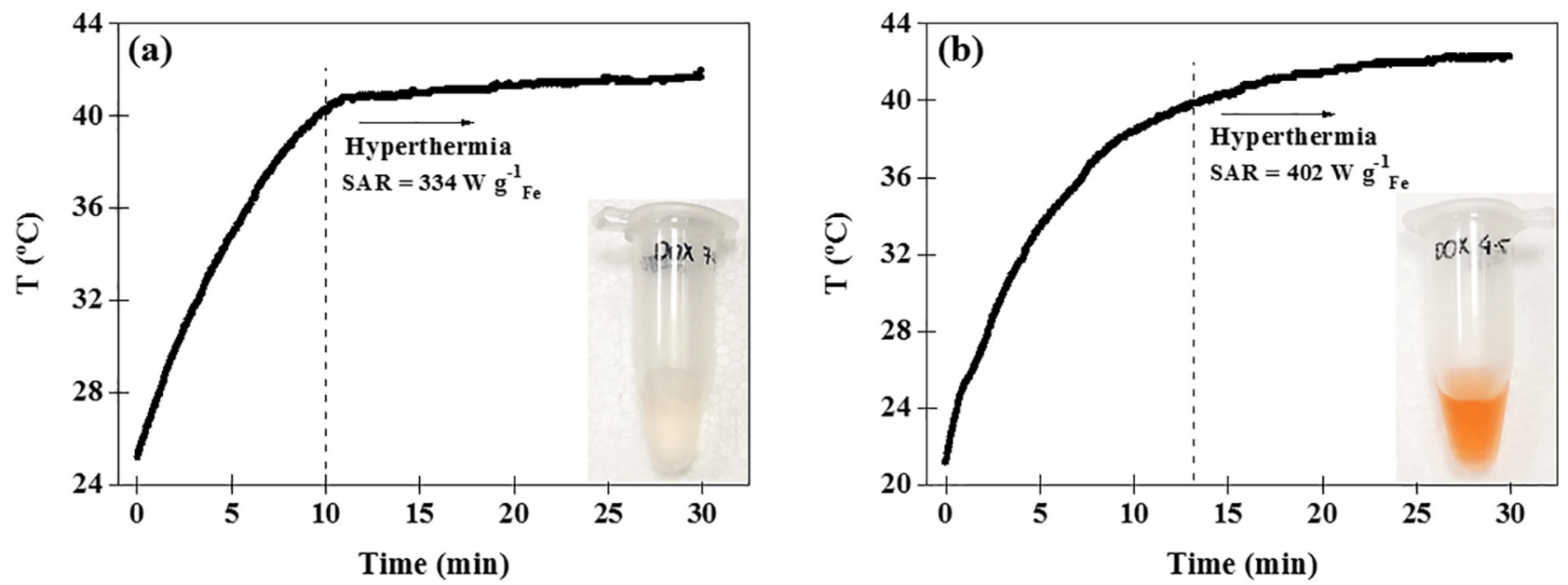

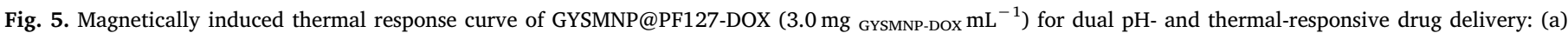

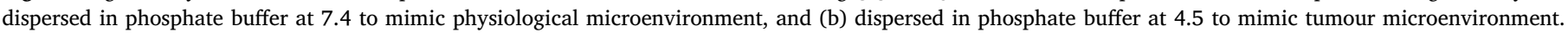

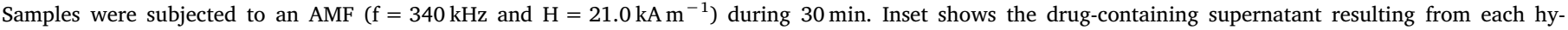
perthermia experiment.

original heating performance.

After each drug release experiment under AMF, samples were centrifuged and the supernatants (cf. insets of Fig. 5(a) and (b)), analysed to determine the amount of DOX released. The results revealed that after 30 min under AMF, just $6.8 \%$ of DOX is released at $\mathrm{pH} 7.4$, while $45.6 \%$ at $\mathrm{pH}$ 4.5. The percentage of DOX released under AMF at $\mathrm{pH} 4.5$, is in the range of that obtained under external heating conditions at $45^{\circ} \mathrm{C}$ in the first $30 \mathrm{~min}$, i.e., $44.0 \%$ (Fig. 4). Even though, under AMF conditions, the temperature reached was slightly lower $\left(40-43^{\circ} \mathrm{C}\right)$ and the length of the test was shorter $(17 \mathrm{~min})$. These better drug release performances observed in AMF can be ascribed to the local heating effects in the vicinity of magnetic nanoparticles, which leads to an increase of the temperature on their surface, without bringing a significant increase in the surrounding medium [15]. Therefore, these results suggest that under an AMF, the local heat generated on the GYSMNP@PF127 surface can help the selective diffusion of loaded DOX into the acidic tumour microenvironment through magnetic hyperthermia. Based on these results, the developed GYSMNP@PF127 material show high promise to act as dual endogenous pH- and exogenous AMF/temperature-responsive drug nanocarrier for controlled drug delivery.

Table 4 shows the comparison of the GYSMNP@PF127 performance with other reported carbon-based nanomaterials reported in literature as magnetic drug delivery systems.

Overall, the developed GYSMNP@PF127 reported in this study exhibits better combined parameters to be applied as efficient nanosystem for the combined treatment of cancer than other carbon-based nanocarriers (Table 4), namely: (i) excellent loading capacity, (ii) high pHsensitivity, (iii) highest total drug release at acidic $\mathrm{pH}$, (iv) highest magnetic saturation, and (v) superparamagnetic behaviour.

\subsection{In vitro cell tests}

\subsubsection{Haemocompatibility assays}

The haemocompatibility of GYSMNP@PF127 was evaluated by haemolysis analysis, ranging the nanocarrier concentration between 10 and $500 \mu \mathrm{g} \mathrm{mL}^{-1}$ in diluted RBCs (red blood cells) during $3 \mathrm{~h}$ at $37^{\circ} \mathrm{C}$. GYSMNP@PF127 shows a very low dose-dependent haemolytic activity even at a very high concentrations $\left(500 \mu \mathrm{g} \mathrm{mL}^{-1}\right)$ with $<4 \%$ of haemolysis, as inferred by the colourless supernatant obtained after $3 \mathrm{~h}$ of incubation at $37^{\circ} \mathrm{C}$ (Fig. S3, ESI). According to the standard ISO 10993-4 that evaluates biological medical devices suitable for blood contact, GYSMNP@PF127 is suitable to be applied directly into the blood stream by exhibiting haemolytic percentages lower than $5 \%$ $[22,61]$. The colloidal stability of the nanocarriers dispersed in the blood fluid for this experiment is shown in Fig. S4, ESI.

\subsubsection{Cell cytotoxicity assays and cellular uptake of drug nanocarriers}

The cell biocompatibility of GYSMNP@PF127 and cytotoxicological effect of GYSMNP@PF127-DOX were investigated by SRB colorimetric assay, where the growth inhibition of several concentrations of the nanocarriers $\left(0.05-50 \mu \mathrm{g} \mathrm{mL}^{-1}\right)$ were assessed, Fig. 6. GYSMNP@ PF127 shows a good biocompatibility behaviour on healthy liver cells PLP2, even after a long exposition time $(48 \mathrm{~h})$ with a GI50 of $58.86 \pm 0.69 \mu \mathrm{g} \mathrm{m}^{-1}$. To assess GYSMNP@PF127-DOX as drug release nanocarrier, research was carried out in tumour liver cell line, HepG2. Fig. 6(b) illustrates a significant drop in the viability of the tumour cells that can be attributed to the increasing concentration of GYSMNP@PF127-DOX, showing a much lower GI50 of $7.34 \pm 3.39 \mu \mathrm{g} \mathrm{mL}^{-1}$ when compared to GYSMNP@PF127. This result suggests that just $7.34 \mu \mathrm{g} \mathrm{mL}^{-1}$ of the loaded nanocarrier system is needed to induce $50 \%$ of reduction of tumour cells. At this concentration, no toxicological effect was observed in healthy cells. This higher cytotoxicity observed for GYSMNP@PF127-DOX is attributed to the DOX released on the tumour cells.

To a better understanding of the therapeutic effect of the DOX released by the GYSMNP@PF127 material over the tumour cells, HepG2 cells were incubated with the drug nanocarrier for 2,4 and $6 \mathrm{~h}$. In addition, the cell nuclei were stained with Hoechst and microtubules were immunolabeled with a monoclonal anti- $\alpha$-tubulin antibody (B512) combined with a secondary goat anti-mouse IgG antibody conjugated with Alexa Fluor 488. Cells were observed using confocal microscopy images obtained with Zeiss Laser Confocal Scanning Microscope. Laser at $405 \mathrm{~nm}$ was used to observe the nucleus, $488 \mathrm{~nm}$ to observe the microtubules and $561 \mathrm{~nm}$ to get the imaging from DOX release. It can be observed (Fig. 7) that the red fluorescence intensity from DOX increases along the incubation time between the nanocarriers and the tumour cells. This observation reveals that the DOX is continuously released from GYSMNP@PF127-DOX nanocarriers. After 6h, the cell nuclei exhibit a strong DOX red fluorescence intensity, suggesting that a high content of DOX is released into the cell cytoplasm and reaches the nucleus after nanoparticle internationalization by endocytosis. The cellular uptake of drug nanocarriers is not only very important for enhancing the drug delivery efficiency, but it is also beneficial for magnetic hyperthermia therapy, allowing a combinatorial thermo-chemotherapeutic effect. 


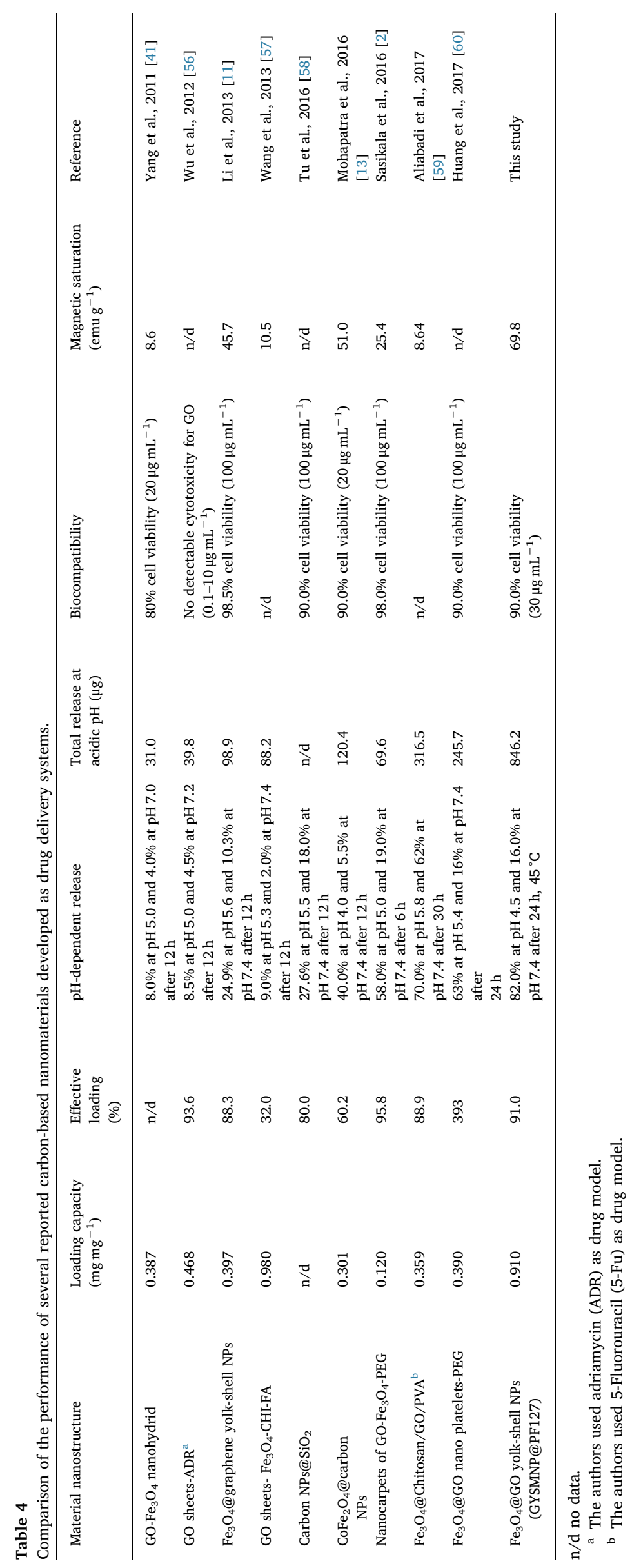




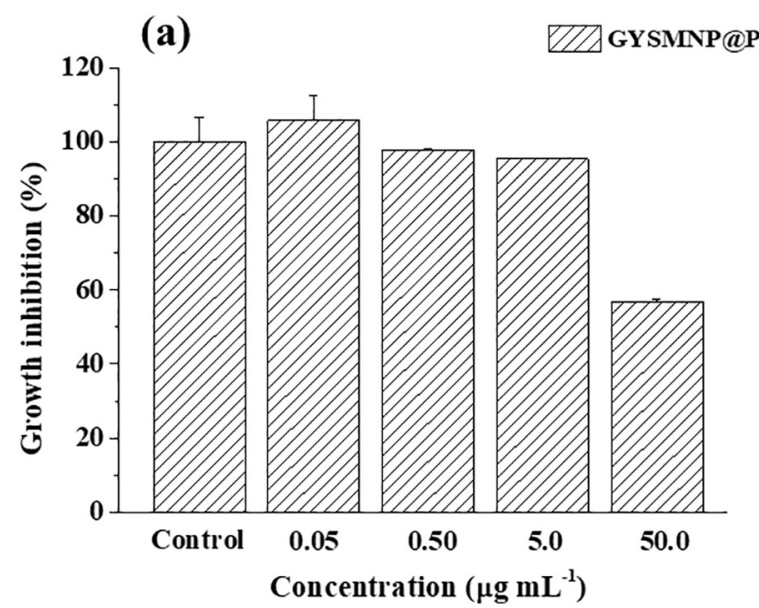

(b)

VIIד GYSMNP@PF127-DOX

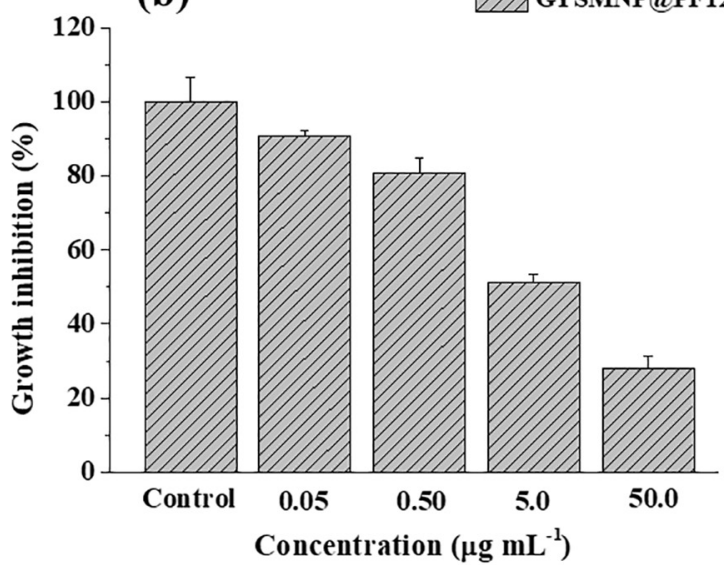

Fig. 6. Cell cytotoxicity assays investigated by SRB colorimetric assay after incubation of (a) GYSMNP@PF127 in healthy liver cell line PLP2; (b) GYSMNP@PF127DOX in tumour liver cell line HepG2, under different concentrations for $48 \mathrm{~h}$.

This combined strategy represents an important step forward in the fight against cancer and highlights this new generation of responsive graphene-based nanocarriers as suitable therapeutic actuators on it. Furthermore, their ability to be further functionalized with targeting molecules opens new opportunities for the treatment of different tumour types. Also, the presented magnetic nanocarriers might be optimized with target molecules, for a more effective nanosystem for the in vivo cancer therapy.

\section{Conclusion}

In this study, hydrophilic graphene-based yolk-shell magnetic nanoparticles (GYSMNP) functionalized with copolymer PF-127, were successfully developed as multifunctional nanocarriers for biomedical applications. To enhance stability and biocompatibility of the graphene-based nanomaterials, samples were chemically activated with nitric acid and functionalized with copolymer PF-127. The results show that this functionalization allowed the increment of the negative charge of the nanocomposites from -17 to $-37 \mathrm{mV}$, which ascribes the incorporation of carboxylic acid groups and surface negative charge, leading to the increase of their colloidal stability in aqueous solutions. Moreover, this functionalization allowed the maintenance of colloidal stability of GYSMNP@PF127 when using salty buffers (as phosphate buffed saline) at different $\mathrm{pH}$, as shown by the AMF hyperthermia
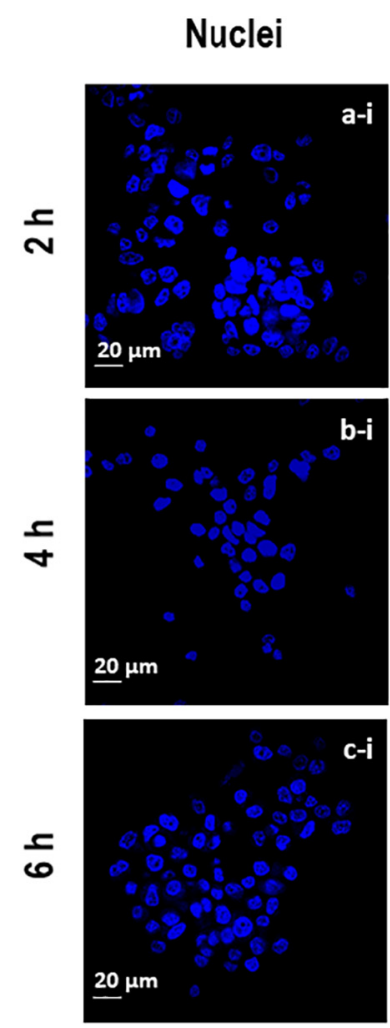

DOX
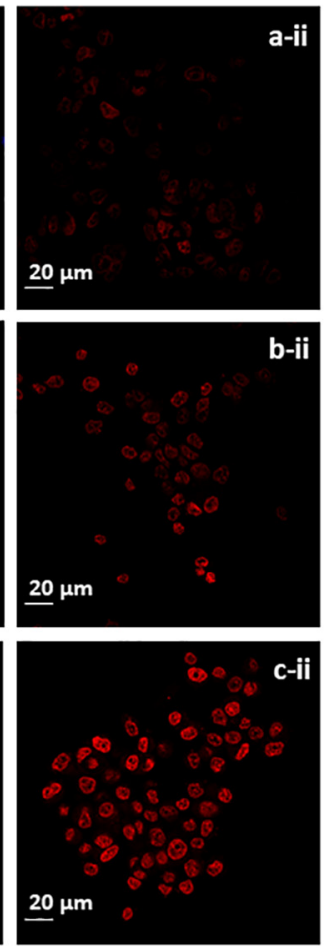

Microtubules
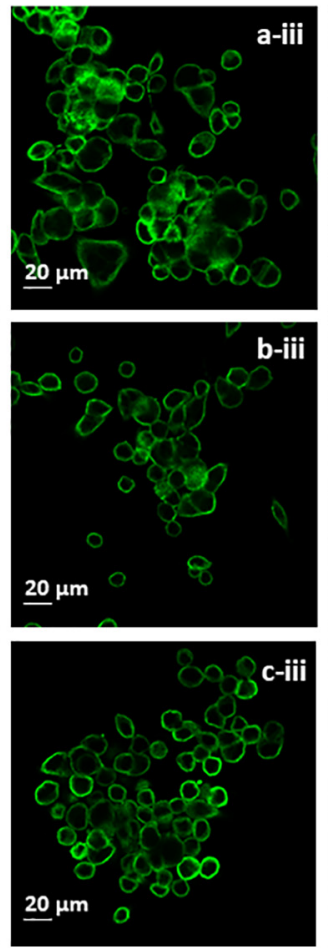

Bright
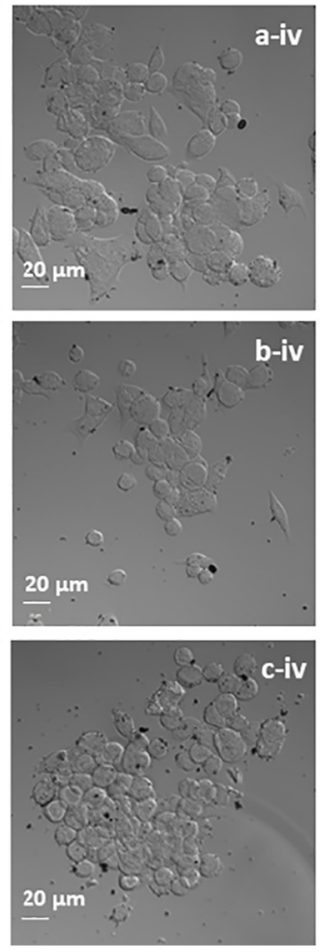

Merge
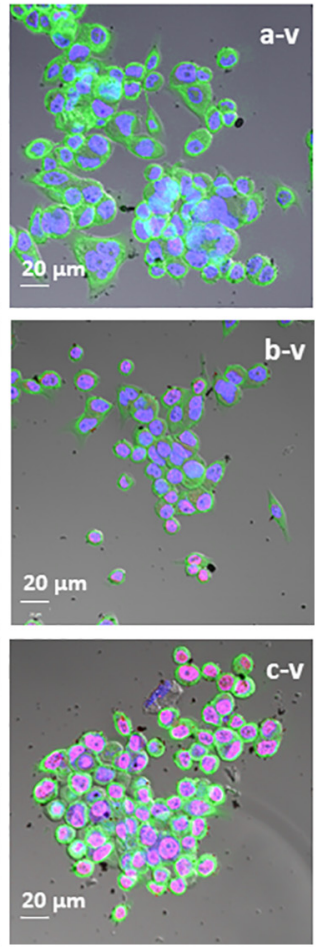

Fig. 7. Confocal microscopy images of HepG2 cells incubated with GYSMNP@PF127-DOX at a concentration of $5 \mu \mathrm{g} \mathrm{mL} \mathrm{m}^{-1}$ during $2 \mathrm{~h}$ (a), $4 \mathrm{~h}$ (b) and $6 \mathrm{~h}$ (c). (i) Cell nuclei stained with Hoechst and excited at $405 \mathrm{~nm}$; (ii) DOX released in HepG2 cells and excited at $561 \mathrm{~nm}$; (iii) Cell microtubules immunolabeled with the monoclonal anti-tubulin antibody (B512) combined with a secondary goat anti-mouse IgG antibody conjugated with Alexa Fluor 488 excited at $488 \mathrm{~nm}$; (iv) HepG2 cells using bright contrast; (v) Cell merge images. 
experiments, where the nanocarriers were able to continuously generate heat during $30 \mathrm{~min}$ of the magnetic heating experiment. The same colloidal stability was verified during the haemocompatibility experiments, were sedimentation was not observed, even at the highest tested concentration (Fig. S4, ESI). Impressively, this hybrid nanomaterial also was found to be an efficient nanoheater at relatively low concentrations, with exceptional drug loading capacity and controlled drug release triggered by the acidic tumour microenvironment. In addition, the external application of an AMF (magnetic hyperthermia) was observed to further induce a drug release, which was more significant at the lowest $\mathrm{pH}$ tested. The dual $\mathrm{pH}$ - and temperature-responsive drug delivery behaviour observed in these nanosystems show a burst release of the drug at mimicked acidic tumour environment, whereas at physiological $\mathrm{pH}$ and temperature, negligible amount of drug is released, confirming that the drug is efficiently retained in the nanocarrier. Furthermore, the developed nanocarriers show good biocompatibility after $48 \mathrm{~h}$ of nanoparticles-cells contact, excellent haemocompatibility and nuclei drug internalization in a short period of time. More interestingly, for future clinical applications, GYSMNP@PF127 can be easily functionalized with other biomolecules in order to enhance its biocompatibility and tumour targeting (i.e., antibodies, aptamers, folic acid, among others). The presented strategy and findings can represent a new way to design and synthesize stable graphene-based materials with novel structures for targeted combinatorial thermo-chemotherapy triggered by abnormal acidic cell microenvironments on tumour site, with the subsequent minimization of side effects on the healthy cells.

\section{Acknowledgments}

This work was financially supported by: Project POCI-01-0145FEDER-006984 - Associate Laboratory LSRE-LCM funded by FEDER through COMPETE2020 - Programa Operacional Competitividade e Internacionalização (POCI) - and by national funds through FCT Fundação para a Ciência e a Tecnologia, and by project NORTE-010145-FEDER-029394, RTChip4Theranostics, supported by Programa Operacional Regional do Norte - Norte Portugal Regional Operational Programme (NORTE 2020), under the PORTUGAL 2020 Partnership Agreement, through the European Regional Development Fund (ERDF) and by Fundação para a Ciência e Tecnologia (FCT), IP. R.O.R. acknowledges the Ph.D. scholarship SFRH/BD/97658/2013 granted by FCT. A.M.T.S acknowledges the FCT Investigator 2013 Programme (IF/ 01501/2013), with financing from the European Social Fund and the Human Potential Operational Programme. G.D. acknowledges financing by Slovene Research Agency (J2-6754). M. B. acknowledges financial funding from POCTEP (Co-operational Programme for Crossborder Cooperation Spain-Portugal). This article is based upon work from COST Action RADIOMAG (TD1402), supported by COST (European Cooperation in Science and Technology).

\section{Appendix A. Supplementary data}

Supplementary data to this article can be found online at https:// doi.org/10.1016/j.msec.2018.07.060.

\section{References}

[1] B. Stewart, C.P. Wild, World Cancer Report 2014, International Agency for Research on Cancer, Lyon, France, 2014.

[2] A.R.K. Sasikala, R.G. Thomas, A.R. Unnithan, B. Saravanakumar, Y.Y. Jeong, C.H. Park, C.S. Kim, Sci. Rep. 6 (2016) 20543.

[3] X. Huang, S. Wu, X. Du, Carbon 101 (2016) 135-142.

[4] R. Tietze, J. Zaloga, H. Unterweger, S. Lyer, R.P. Friedrich, C. Janko, M. Pöttler, S. Dürr, C. Alexiou, Biochem. Biophys. Res. Commun. 468 (2015) 463-470.

[5] Z. Li, E. Ye, David R. Lakshminarayanan, X.J. Loh, Small 12 (2016) 4782-4806.

[6] S. Mura, J. Nicolas, P. Couvreur, Nat. Mater. 12 (2013) 991-1003.

[7] C. Tao, Y. Zhu, Dalton Trans. 43 (2014) 15482-15490.

[8] Y. Xu, Y. Zhu, S. Kaskel, RSC Adv. 5 (2015) 99875-99883.
[9] Z. Tian, X. Yu, Z. Ruan, M. Zhu, Y. Zhu, N. Hanagata, Microporous Mesoporous Mater. 256 (2018) 1-9.

[10] D. Chen, C.A. Dougherty, K. Zhu, H. Hong, J. Control. Release 210 (2015) 230-245.

[11] S. Li, J. Zheng, D. Chen, Y. Wu, W. Zhang, F. Zheng, J. Cao, H. Ma, Y. Liu, Nanoscale 5 (2013) 11718-11724.

[12] X. Yu, Y. Zhu, Sc. Tech. Adv. Mater. 17 (2016) 229-238.

[13] S. Mohapatra, S.R. Rout, R.K. Das, S. Nayak, S.K. Ghosh, Langmuir 32 (2016) 1611-1620.

[14] J. Liu, Z. Luo, J. Zhang, T. Luo, J. Zhou, X. Zhao, K. Cai, Biomaterials 83 (2016) 51-65.

[15] A. Hervault, A.E. Dunn, M. Lim, C. Boyer, D. Mott, S. Maenosono, N.T.K. Thanh, Nanoscale 8 (2016) 12152-12161.

[16] S. Chandra, G. Noronha, S. Dietrich, H. Lang, D. Bahadur, J. Magn. Magn. Mater. 380 (2015) 7-12.

[17] Y. Wang, R. Zhao, S. Wang, Z. Liu, R. Tang, Biomaterials 75 (2016) 71-81.

[18] S. Li, J. Guo, R.A. Patel, A.L. Dadlani, R.M. Leblanc, Langmuir 29 (2013) 5742-5748.

[19] A. Pitto-Barry, N.P.E. Barry, Polym. Chem. 5 (2014) 3291-3297.

[20] Q. Zhou, Z. Zhang, T. Chen, X. Guo, S. Zhou, Colloids Surf. B 86 (2011) 45-57.

[21] A. Meshkini, H. Oveisi, Colloids Surf. B 158 (2017) 319-330.

[22] R.O. Rodrigues, M. Bañobre-López, J. Gallo, P.B. Tavares, A.M.T. Silva, R. Lima, H.T. Gomes, J. Nanopart. Res. 18 (2016) 1-17.

[23] W.-J. Liu, Y.-X. Liu, X.-Y. Yan, G.-P. Yong, Y.-P. Xu, S.-M. Liu, J. Mater, Chem. A 2 (2014) 9600-9606.

[24] G.M. Mutlu, G.R.S. Budinger, A.A. Green, D. Urich, S. Soberanes, S.E. Chiarella, G.F. Alheid, D.R. McCrimmon, I. Szleifer, M.C. Hersam, Nano Lett. 10 (2010) 1664-1670.

[25] S. Brunauer, P.H. Emmett, E. Teller, J. Am. Chem. Soc. 60 (1938) 309-319.

[26] F. Rodríguez-Reinoso, A. Linares-Solano, Chemestry and Physics of Carbon, Marcel Dekker Inc., New York, 1989.

[27] R.S. Ribeiro, Z. Frontistis, D. Mantzavinos, D. Venieri, M. Antonopoulou, I. Konstantinou, A.M.T. Silva, J.L. Faria, H.T. Gomes, Appl. Catal. B 199 (2016) $170-186$.

[28] J. Siepmann, F. Siepmann, Int. J. Pharm. 364 (2008) 328-343.

[29] M. Szekeres, E. Illés, C. Janko, K. Farkas, I.Y. Tóth, D. Nesztor, I. Zupkó, I. Foldesi, C. Alexiou, E. Tombácz, J. Nanomed. Nanotechnol. 6 (2015) 1000252.

[30] Y.V. Kolen'ko, M. Bañobre-López, C. Rodríguez-Abreu, E. Carbó-Argibay, A. Sailsman, Y. Piñeiro-Redondo, M.F. Cerqueira, D.Y. Petrovykh, K. Kovnir, O.I. Lebedev, J. Rivas, J. Phys. Chem. C 118 (2014) 8691-8701.

[31] X. Zhang, Y. Wang, Y. Zhao, L. Sun, Mater. Sci. Eng. C 77 (2017) 19-26.

[32] R.M.V. Abreu, I.C.F.R. Ferreira, R.C. Calhelha, R.T. Lima, M.H. Vasconcelos, F. Adega, R. Chaves, M.-J.R.P. Queiroz, Eur. J. Med. Chem. 46 (2011) 5800-5806.

[33] B. Svobodova, L. Barros, R.C. Calhelha, S. Heleno, M.J. Alves, S. Walcott, M. Bittova, V. Kuban, I.C.F.R. Ferreira, Ind. Crop. Prod. 95 (2017) 365-373.

[34] A. Monks, D. Scudiero, P. Skehan, R. Shoemaker, K. Paull, D. Vistica, C. Hose, J. Langley, P. Cronise, A. Vaigro-Wolff, M. Gray-Goodrich, H. Campbell, J. Mayo, M. Boyd, J. Natl. Cancer Inst. 83 (1991) 757-766.

[35] W. Voigt, Sulforhodamine B Assay and Chemosensitivity, in: R.D. Blumenthal (Ed.), Chemosensitivity: In Vitro Assays, Humana Press, Totowa, NJ, 2005, pp. 39-48.

[36] S.A.C. Lima, A. Gaspar, S. Reis, L. Durães, Mater. Sci. Eng. C 75 (2017) 1420-1426.

[37] L. Pradhan, R. Srivastava, D. Bahadur, Acta Biomater. 10 (2014) 2976-2987.

[38] G. Bharath, R. Madhu, S.-M. Chen, V. Veeramani, D. Mangalaraj, N. Ponpandian, J. Mater. Chem. A 3 (2015) 15529-15539.

[39] L.M. Pastrana-Martínez, S. Morales-Torres, V. Likodimos, P. Falaras, J.L. Figueiredo, J.L. Faria, A.M.T. Silva, Appl. Catal. B 158-159 (2014) 329-340.

[40] N. Kumar Sudesh, S. Das, C. Bernhard, G.D. Varma, Supercond. Sci. Technol. 26 (2013) 095008.

[41] X. Yang, Y. Wang, X. Huang, Y. Ma, Y. Huang, R. Yang, H. Duan, Y. Chen, J. Mater Chem. 21 (2011) 3448-3454.

[42] J.L. Figueiredo, J. Mater. Chem. A 1 (2013) 9351-9364.

[43] Q. Dou, A. Abdul Karim, X. Loh, Polym. J. 8 (2016) 341.

[44] A.C. Ferrari, J.C. Meyer, V. Scardaci, C. Casiraghi, M. Lazzeri, F. Mauri, S. Piscanec, D. Jiang, K.S. Novoselov, S. Roth, A.K. Geim, Phys. Rev. Lett. 97 (2006) 187401.

[45] A.C. Ferrari, D.M. Basko, Nat. Nanotechnol. 8 (2013) 235-246.

[46] A.C. Ferrari, J. Robertson, Phys. Rev. B 61 (2000) 14095-14107.

[47] A. Kaniyoor, S. Ramaprabhu, AIP Adv. 2 (2012) 032183.

[48] P. Mohan, N. Rapoport, Mol. Pharm. 7 (2010) 1959-1973.

[49] M. Mahdavi, F. Rahmani, S. Nouranian, J. Mater. Chem. B 4 (2016) 7441-7451.

[50] M. Gisbert-Garzarán, M. Manzano, M. Vallet-Regí, Bioengineering 4 (2017) 1-27.

[51] A. Adnan, R. Lam, H. Chen, J. Lee, D.J. Schaffer, A.S. Barnard, G.C. Schatz, D. Ho, W.K. Liu, Mol. Pharm. 8 (2011) 368-374.

[52] M.S.H. Akash, K. Rehman, S. Chen, Polym. Rev. 54 (2014) 573-597.

[53] W. Rao, W. Zhang, I. Poventud-Fuentes, Y. Wang, Y. Lei, P. Agarwal, B. Weekes, C. Li, X. Lu, J. Yu, X. He, Acta Biomater. 10 (2014) 831-842.

[54] Y. Oh, M.S. Mooethy, P. Manivasagan, S. Bharathiraja, J. Oh, Biochimie 133 (2017) 7-19.

[55] P. Presa, Y. Luengo, M. Multigner, R. Costo, M.P. Morales, G. Rivero, A. Hernando, J. Phys. Chem. C 116 (2012) 25602-25610.

[56] J. Wu, Y.S. Wang, X.Y. Yang, Y.Y. Liu, J.R. Yang, R. Yang, N. Zhang, Nanotechnology 23 (2012) 355101.

[57] Z. Wang, C. Zhou, J. Xia, B. Via, Y. Xia, F. Zhang, Y. Li, L. Xia, Colloids Surf. B 106 (2013) 60-65.

[58] X. Tu, L. Wang, Y. Cao, Y. Ma, H. Shen, M. Zhang, Z. Zhang, Carbon 97 (2016) 35-44.

[59] M. Aliabadi, H. Shagholani, A. Yunessnia lehi, Int. J. Biol. Macromol. 98 (2017) 287-291.

[60] Y.-S. Huang, Y.-J. Lu, J.-P. Chen, J. Magn. Magn. Mater. 427 (2017) 34-40.

[61] Q. Wang, M. Shen, T. Zhao, Y. Xu, J. Lin, Y. Duan, H. Gu, Sci. Rep. 5 (2015) 7774. 